\title{
SOEP
}

SOEPpapers

SOEPDangers
on Multidisciplinary Panel Data Research

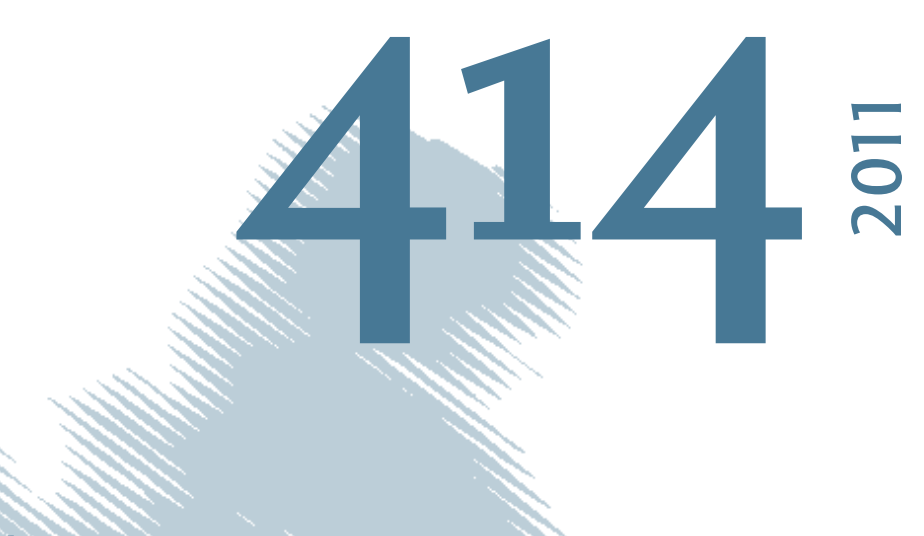

\section{Predicting the Trend of Well-Being in Germany: How Much Do Comparisons, Adaptation and Sociability Matter?}




\section{SOEPpapers on Multidisciplinary Panel Data Research}

at DIW Berlin

This series presents research findings based either directly on data from the German SocioEconomic Panel Study (SOEP) or using SOEP data as part of an internationally comparable data set (e.g. CNEF, ECHP, LIS, LWS, CHER/PACO). SOEP is a truly multidisciplinary household panel study covering a wide range of social and behavioral sciences: economics, sociology, psychology, survey methodology, econometrics and applied statistics, educational science, political science, public health, behavioral genetics, demography, geography, and sport science.

The decision to publish a submission in SOEPpapers is made by a board of editors chosen by the DIW Berlin to represent the wide range of disciplines covered by SOEP. There is no external referee process and papers are either accepted or rejected without revision. Papers appear in this series as works in progress and may also appear elsewhere. They often represent preliminary studies and are circulated to encourage discussion. Citation of such a paper should account for its provisional character. A revised version may be requested from the author directly.

Any opinions expressed in this series are those of the author(s) and not those of DIW Berlin. Research disseminated by DIW Berlin may include views on public policy issues, but the institute itself takes no institutional policy positions.

The SOEPpapers are available at

http://www.diw.de/soeppapers

\section{Editors:}

Joachim R. Frick (Empirical Economics)

Jürgen Schupp (Sociology, Vice Dean DIW Graduate Center)

Gert G. Wagner (Social Sciences)

Conchita D'Ambrosio (Public Economics)

Denis Gerstorf (Psychology, DIW Research Professor)

Elke Holst (Gender Studies)

Frauke Kreuter (Survey Methodology, DIW Research Professor)

Martin Kroh (Political Science and Survey Methodology)

Frieder R. Lang (Psychology, DIW Research Professor)

Henning Lohmann (Sociology, DIW Research Professor)

Jörg-Peter Schräpler (Survey Methodology, DIW Research Professor)

Thomas Siedler (Empirical Economics, DIW Graduate Center)

C. Katharina Spieß (Empirical Economics and Educational Science)

ISSN: 1864-6689 (online)

German Socio-Economic Panel Study (SOEP)

DIW Berlin

Mohrenstrasse 58

10117 Berlin, Germany

Contact: Uta Rahmann | soeppapers@diw.de 


\title{
Predicting the Trend of Well-Being in Germany: How Much Do Comparisons, Adaptation and Sociability Matter?
}

\author{
Stefano Bartolini \\ Department of Economics, University of Siena, Italy \\ Population et emploi, CEPS/INSTEAD, Luxembourg
}

Ennio Bilancini*

Department of Economics, University of Modena and Reggio Emilia, Italy

Francesco Sarracino ${ }^{\dagger}$

Population et emploi, CEPS/INSTEAD, Luxembourg

\begin{abstract}
Using longitudinal data from the German Socio-Economic Panel, we estimate the variation of subjective well-being experienced by Germans over the last two decades testing the role of some of the major correlates of people's well-being. Our results suggest that the variation of Germans' well-being between 1996 and 2007 is well predicted by changes over time of income, demographics and social capital. The increase in social capital predicts the largest positive change in subjective well-being. Income growth, also predicts a substantial change in subjective well-being, but it is compensated for about three fourths by the joint negative predictions due to income comparison and income adaptation. Finally, we find that aging of the population predicts the largest negative change in subjective well-being. This result appears to hinge on the large loss of satisfaction experienced by individuals in old age.
\end{abstract}

Keywords: subjective well-being; life satisfaction; social capital; sociability; relational goods; relative income; social comparisons; income adaptation; SOEP.

JEL classification codes: $\mathrm{I} 3$; $\mathrm{O} 1$.

\footnotetext{
*Corresponding author: ennio.bilancini@unimore.it

${ }^{\dagger}$ Francesco Sarracino is supported by an AFR grant (contract PDR-09-075) by the National Research Fund, Luxembourg cofunded under the Marie Curie Actions of the European Commission (FP7-COFUND).
} 


\section{Introduction}

In this paper we estimate the overall variation of German subjective well-being (SWB) between 1996 and 2007, as it is predicted by the changes over time in each of its statically significant correlates. Our aim is to assess the relative importance of each SWB correlate in explaining the trend of German SWB.

Strong interest in the trends of SWB has been motivated by one astonishing stylized fact:1. the lack of substantial growth of SWB in the long-term in many important Western countries. For instance, decades-long time series suggest that SWB did not increase significantly in US, UK and Germany (Easterlin, 1974, Blanchflower and Oswald, 2004b, Layard and Nickell, 2009, see). This evidence is surprising and disappointing if considered in the light of the dramatic economic growth experienced by Western countries during post-World War II. Available evidence at the micro-level confirms the predictions of economic theory regarding the positive relationship between individuals' well-being and income. Indeed, at any point in time individuals with higher incomes report, on average, a higher SWB (Easterlin, 1974). So, why does not the average well-being grow when the average income grows? Such a contrast between cross-sectional evidence and time series evidence may seem paradoxical, and in fact it has been labelled as the "Easterlin paradox". What does explain such a paradox?

Two non-alternative explanations have been put forward so far: one based on hedonic adaptation and the other based on social comparisons.

The explanation based on hedonic adaptation presumes that changes in people's living conditions (for example concerning their economic conditions) have only a transitory effect on their well-being because people tend to adapt to their past experiences (Frederick and Loewenstein, 1999, Clark et al., 2008). The same is supposed to hold for nations (Blanchflower, 2008). In other words, this theory posits that, as time goes by, there exists an adaptation process that sooner or later erodes the benefits of any increase in income.

The explanation based on social comparisons presumes that what matters to people is not their absolute income level but their income level relative to the income level of a selected group of individuals with whom they compare (Veblen, 1899, Duesenberry, 1949, Diener et al.,

\footnotetext{
${ }^{1}$ See Dolan et al. (2008) for a recent survey on the determinants of subjective well-being.
} 
1993, Layard, 2005, Di Tella et al., 2007, Ferrer-i-Carbonell, 2005).2 This group of people represents a sort of reference point. Moreover, it has been suggested that the mechanism of comparison is such that people's relative gains and losses tend to cancel each other out, resulting in no significant shifts for the well-being of the society as a whole. Therefore, a rise in the incomes of all does not necessarily increase the well-being of all.

Both these explanations have well-established roots and, so far, they have been quite supported by cross-sectional evidence (see Clark et al., 2008, and references therein).

Recent developments in social sciences point towards a further potential explanatory factor:

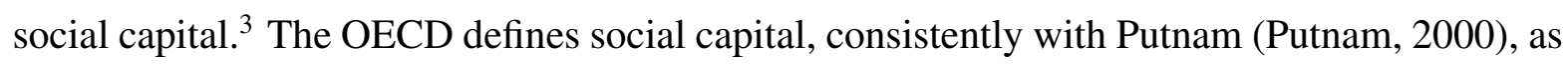
"networks together with shared norms, values and understandings that facilitate co-operation within or among groups." (OECD, 2001, p.41). This definition refers to a very far-reaching concept. Indeed, in its statistical embodiments, social capital includes measures that are quite dissimilar, ranging from voter turnout, to trust in institutions, to the quantity and quality of intimate relationships and social bonds among individuals. Recent studies document that this latter component of social capital - the relational one, also labelled as "relational goods" (Gui and Sugden, 2005, Uhlaner, 1989) - is strongly correlated with SWB (see the pioneering studies by Helliwell (2001, 2006) and Helliwell and Putnam (2004); (see also Bruni and Stanca, 2008, Becchetti et al., 2008, Bartolini et al., 2011)). Moreover, Becchetti et al. (2011) provided a causal analysis showing that social capital has a strong impact on SWB.

Beyond absolute income, reference income, individual's past income, and social capital, other important cross-sectional correlates of SWB have been identified, such as unemployment (Frey and Stutzer, 2002), health (Deaton, 2008), education, familiar status (Blanchflower and Oswald, 2004a), institutional settings (Frey and Stutzer, 2000), etc. However, the first four correlates deserve special attention as plausible drivers of the trends of SWB. The reason is that, differently from the other correlates of SWB, they tend to be strongly trended. For instance, unemployment exhibits substantial short term fluctuations but small variations in the long run. Instead, all three income variables are systematically driven upwards by economic growth. Also, social capital can be trended, as popularized by Putnam (2000). More precisely, Put-

\footnotetext{
${ }^{2}$ Corazzini et al. (2011) show that also the perception of poverty is reference-based, with people in higher income countries giving more relevance to reference income.

${ }^{3}$ See Bartolini and Bonatti (2008), Antoci et al. (2011), and Bilancini and D'Alessandro (2011) recent theoretical investigations on the role of social capital.
} 
nam documents a decades-long decline in US social capital. Such evidence has been disputed by Ladd (1996) but have finally proven to be robust. Paxton (1999), Robinson and Jackson (2001), Costa and Kahn (2003) by observing a variety of indicators, confirm that social capital is declining in the US. Bartolini et al. (2011) show that a large portion of the decline in US happiness in the last thirty years is predicted by the decline in social capital.

The aim of the present work is to quantify the relative importance of statistically significant correlates of SWB in predicting the trend of life satisfaction in Germany during the period 1996-2007. In particular, we focus on the role played by absolute income, reference income, individuals' past incomes and social capital.

We employ data from the German Socio-Economic Panel (SOEP), one of the main sources of evidence on the relevance of adaptation and social comparisons (Ferrer-i-Carbonell, 2005, Vendrik and Woltjer, 2007, Clark et al., 2008, Layard and Nickell, 2009). Moreover, the SOEP is rich in social capital indicators and indeed it has been used to show the importance of such variables for well-being (Becchetti et al., 2008, 2011). We emphasize that the SOEP is a longitudinal dataset. This feature allows us to control for fixed individual unobserved heterogeneity and to test further hypothesis on the relationship between life satisfaction and its correlates.

Our results suggest an important role for absolute income, reference income, past income, and social capital. All these variables crucially contribute to the correct prediction of the trend of SWB. In particular, we find that three fourths of the benefits predicted by income growth are off-set by the negative effects predicted by the growth in reference income and own's past income. Social capital appears to be the largest positive predictor of SWB. In addition to these four important variables, we document a substantial role for demographic variables. In particular, we find that the ageing of population predicts the largest negative change in SWB. This result appears to crucially hinge on the loss of satisfaction experienced in very old age.

If we assume that causality runs from our regressors to SWB, the present results suggest that economic growth - which was substantial - had a limited positive impact on the trend of SWB, and that the increase in social capital - which was instead modest - had a limited positive impact too. In this situation, demographic factors, and specifically the ageing of the population, largely affected the decreasing Germans' subjective well-being.

It is worth stressing that our estimates might be affected by endogeneity problems and that 
we should be cautious in drawing conclusions. However, we provide some tests supporting the hypothesis that the causal relationship from social capital to SWB is strong and significant.

The paper is organized as follows. Section 2 discusses concepts, data and presents the econometric strategy that we followed. Results are presented in section 3 , while some robustness checks are reported in section 4 . Finally, section 5 provides a summary of results and a few final remarks.

\section{Data and empirical strategy}

In this study we employ the SOEP dataset. $]^{4}$ Our choice has been mainly driven by the longitudinal structure of the SOEP which allows us both to control for fixed unobservable characteristics at the individual level and to test for the role of hedonic adaptation. Moreover, the SOEP contains a sufficient number of observations for social capital indicators at the individual level, making it possible to explore the role of social capital.5

In order to estimate the change in German SWB bewteen 1996 and 2007 which is predicted by the trend of its statistically significant correlates we adopt the two-steps strategy which has been already applied in Di Tella and MacCulloch (2008a) and Bartolini et al. (2011). First, we estimate a baseline equation quantifying partial correlations between SWB and its predictors. Second, we calculate the product between the estimated coefficients of such predictors that turn out to be statistically significant and their variation over the period 1996-2007. In this way we obtain the change in SWB which is predicted by the change in each regressor with a statistically significant coefficient.

\subsection{The data}

The SOEP is a longitudinal survey of households and persons in the Federal Republic of Germany and it is conducted on a yearly basis by the DIW in Berlin 6 The SOEP focuses on micro-data about demographic, economic, social, and political variables. The survey started

\footnotetext{
${ }^{4}$ The data were extracted using the add-on package PanelWhiz v2.0 (Nov 2007) for Stata. PanelWhiz was written by Dr. John P. Haisken-DeNew (john@ panelwhiz.eu). The PanelWhiz generated .do files to retrieve the SOEP data used here are available upon request to the authors. Any data or computational errors in this paper are our own. Please refer to Haisken-DeNew and Hahn (2010) for a detailed description of PanelWhiz.

${ }^{5}$ For more details on the SOEP see Frick et al. (2007) and Wagner et al. (2007).

${ }^{6} \mathrm{http} / / / \mathrm{www} . \mathrm{diw} \cdot \mathrm{de}$
} 
in 1984 and initially was designed for West Germany only, including about 6000 households. However, since June 1990 the sampling was extended to include about 2000 East German households.

For our baseline regression, we focus on the sub-samples constituted by residents in West and East Germany in the period 1994-2007. We exclude sub-samples dedicated to foreigners, immigrants, high income households, as well as refreshments. In other words, we only consider the Germans participating to the initial East and West samples. The reason is that the sub-samples that we discarded are selected with a large use of oversampling to allow the assessment of specific issues concerning sub-populations. Using these sub-samples may result in biases due to sample selection. However, our prediction of the trend of SWB takes into account a correct representation of the German population by using the whole sample with appropriate population weights.

Due to both sample constraints and data missing we end up using 59527 person-year observations out of 222404 available. The years for which we actually have observations for all variables of interest are 1994, 1996, 1997, 1999, 2001, 2005, and 2007. This substantial loss of information with respect to yearly data is mostly due to the fact that indicators of social capital are not recorded on a yearly basis.

As a robustness check, in subsection 4.2 we repeat the analysis considering only the subsample made of West Germans which allows to extend the period to 1988-2007.

\subsection{Estimation of the SWB equation}

We posit that an individual's SWB is determined by the following function:

$$
S W B_{i, t}=v\left(X_{i, t}, y_{i, t}, \bar{y}_{i, t}, y_{i, t-k}, S C_{i, t}\right)
$$

where the indices $i$ and $t$ denote the individual and the year, respectively; $y$ is a variable representing absolute income, $\bar{y}$ is a proxy for reference income, $X$ is a set of social and demographic characteristics, and $S C$ stands for a set of social capital variables at the individual level. Note that $i$ 's income appears twice: $y_{i, t}$ is $i$ 's income in year $t, y_{i, t-k}$ is $i$ 's income $k$ years before year $t$.

We do not observe well-being directly, but only a proxy of it, namely a measure of SWB. In particular, we rely on the following question provided in the SOEP: "And finally, we would 
like to ask you about your satisfaction with your life in general. Please answer by using the following scale, in which 0 means totally unhappy, and 10 means totally happy. How happy are you at present with your life as a whole?" As the answer takes discrete values, from 0 to 10, we are in a typical case of latent dependent variable proxied by a multinomial ordered variable. Because of such a latency and the longitudinal characteristic of the dataset, best statistical practice would suggest the use of an ordered probit model augmented with individual random effects and Mundlak's corrections (see, e.g., Ferrer-i-Carbonell, 2005) or, alternatively, an ordered logit model with individual fixed effects. However, it is now well documented that in such cases an OLS model with individual fixed effects provides equivalent results (Ferrer-i-Carbonell and Frijters, 2004a). Therefore, we resort to the use of an OLS model with individual fixed effects to estimate the following baseline equation:

$$
S W B_{i, t}=\alpha+\beta_{1} \cdot X_{i, t}^{d}+\gamma_{1} \cdot \ln \left(y_{i, t}\right)+\gamma_{2} \cdot \ln \left(\bar{y}_{i, t}\right)+\gamma_{3} \cdot \ln \left(y_{i, t-k}\right)+\delta \cdot S C_{i, t}+e_{i, t}
$$

In addition to the variables specified in equation (1) we add a set of dummies to control for the fixed effects of years, Land, and former West Germany. To indicate this in equation (2) we introduce the superscript $d$ which means that we augmented $X$ with the listed dummy variables. Other variables considered in $X$ are: age, marital status, work status, household size, presence of children, and years of education. Descriptive statistics are reported in table 10 in the Appendix.

Absolute income $y$ is operationalized as the SOEP variable "adjusted monthly household net income". "Adjusted" stands for the fact that income is real and converted in euro of year 2000. Following previous literature (see, e.g., Ferrer-i-Carbonell, 2005, Vendrik and Woltjer, 2007), we use household income rather than personal income because it better accounts for the individual's real access to economic resources.

\subsection{Reference income}

We operationalize reference income of individual $i$ in year $t$ as the average income of $i$ 's reference group in year $t$. The reference group of individual $i$ in year $t$ is constructed as the sub-sample of people living in $i$ 's region (West or East) in year $t$ that have about $i$ 's education and age. More precisely, three categories of education are used according to years of education: 
less than 11, between 11 and 12, and 13 or more. Similarly, three age brackets are considered: younger than 30 , between 31 and 60 , and 61 or older.

The combination of these characteristics generates 378 different reference groups. The mean size of these groups is of 969 individuals, the median is 683 and the minimum size is 70 . We opted for having only three age categories because this allows us to condition the reference group on the region of residence as well while retaining groups of non-negligible sizes.

As convincingly argued by Falk and Knell (2004), reference groups are likely to be endogenous. However, one's reference group is likely to change rather slowly and in accordance with the change in one's lifestyle. Thus, our definition of reference group should work sufficiently well for our purposes.

Another issue is what measure of income should be used to calculate reference income. We use household income as done in Ferrer-i-Carbonell (2005), Vendrik and Woltjer (2007) and Layard and Nickell (2009). This amounts to assume that the likelihood of having characteristics similar to $i$ 's ones is greater for people in $i$ 's household than for an individual randomly selected from the rest of the population.

Of course, other definitions of reference group are possible. For instance, one could further refine the reference group by also considering gender (Ferrer-i-Carbonell, 2005, Vendrik and Woltjer, 2007). Alternatively, one can focus especially on the community or region of residence (Diener et al., 1993, Stutzer, 2004, Luttmer, 2005), people's cohort (McBride, 2001), or people's state or country (Easterlin, 1995, Blanchflower and Oswald, 2004b). Finally, individuals might have more than one reference group (Kapteyn and Wansbeek, 1985, Vendrik and Hirata, 2007). D'Ambrosio and Frick (2008) propose an original definition of reference group which allows to distinguish relativity effects based on social comparisons from those having an information basis. Overall, they find that the SWB of an individual is negatively affected by the comparison with permanently richer individuals. Conversely, the presence of newly richer individuals plays the informational role described in Hirschman's tunnel effect only for those individuals that experience an increasing income.7

Finally, Di Tella et al. (2007) propose, in alternative to usual measures of relative income, the use of the Occupational Prestige Score (OPS) which is recognized as a measure of social

\footnotetext{
${ }^{7}$ For more details about the tunnel effect see Hirschman (1973) or, more recently, Senik (2004) and Caporale et al. (2009).
} 
standing. The OPS is a coded ranking, often applied by sociologists, which is based on an individual's type of job. This measure is certainly interesting and deserves attention but it reasonably captures many other aspects of the working and social life beyond relative income. Since one of our objectives is to single out the net effect of income on SWB, the OPS does not seem an appropriate choice.

\subsection{Lagged income}

We control for income adaptation by including one's own past household income in the SWB equation. Several specifications of this variable are possible. In line with what found by Layard and Nickell (2009), the specification of past household income that seems more relevant to Germans' reported SWB is a three-years-in-the-past income, i.e., $y_{i, t-3}$ for individual $i$ at time $t$.

Beyond Layard and Nickell (2009), other two papers attempt to measure the role of past income on current SWB using the SOEP, namely Di Tella et al. (2007) and Di Tella and MacCulloch (2008b). Di Tella et al. (2007) apply all lags between 1 and 4 years in the past; Di Tella and MacCulloch (2008b) apply all lags between 1 and 7 years in the past. While the first paper offers, in addition, the analysis of adaptation to one's own social status (as measured by the OPS), the second paper investigates the issue of income adaptation when basic needs are satisfied, exploring a broader sample of subjects than what done in the present paper (including also the the World Gallup Poll and the Eurobarometer for 16 European countries). The fundamental conclusion of both papers is that after about 5 years adaptation is almost complete for certain social groups, while it is never complete for others. On balance, evidence suggests that adaptation exists and is relevant but is not complete, at least when the whole population is considered.

Finally, we stress that our decision to apply a three-years-in-the-past income variable to capture income adaptation is not an ad hoc choice. To prove this in subsection 4.1 we report estimations of equation (2) where $y_{i, t-k}$ is alternatively specified with $k$ equal to $1,2,4,5,6$, 7 and 8 . 


\subsection{Indicators of social capital}

In principle, social capital comprises measures of an individual's or group's networks, personal connections, general trust, and civic involvement (Helliwell and Putnam, 2004, Sabatini, 2009). However, the SOEP does not provide time series for indicators of all such components of social capital. More precisely, the available indicators are only about non-market relationships among individuals, also referred to as indicators of social interactions (Durlauf, 2001, 2002), relational goods (Uhlaner, 1989, Gui and Sugden, 2005, Bruni and Stanca, 2008), or sociability (Becchetti et al., 2008). Therefore, we restrict our attention to these indicators. Specifically, we consider the monthly frequency of social activities such as attending religious events, attending cultural events, attending cinema, pop concerts and similar, participating actively in sports, attending social gatherings, helping out friends, performing volunteer work, and participating in local politics. The SOEP has a dedicated indicator for each of these activities, where respondents are asked to say which of the following frequencies best fits their lifestyle: every day (1), every week (2), every month (3), less frequently (4), or never (5).

For each of the eight indicators we create a dummy variable which is set equal to 1 if the respondent perform the mentioned activity at least once a month, and 0 otherwise. We have chosen the reported frequency "at least once a month" as a threshold because it well captures the sample variation. This can be seen in table 1 which illustrates the frequencies of social activities for the representative sample of Germans during the considered period.

Becchetti et al. (2008) and Becchetti et al. (2011) are especially close to our approach as they investigate the relationship between sociability and SWB using the SOEP. In both papers only five of the eight indicators mentioned above are employed to construct a Relational Time Index which is then applied in a bunch of causality tests. More precisely, the following indicators are excluded: (i) attending cinema, pop concerts, dance hall and related events, (ii) helping out friends or relatives, and (iii) participating in local political activities. It is true that these indicators do not capture only a relational dimension but also other aspects of life that are reasonably relevant to SWB. Listening to good music or tuning one's body to music might increase SWB by itself. However, the relational content of these activities has a lot to do with their impact on well-being. Paraphrasing Lim and Putnam (2008), dancing alone is no fun. 


\begin{tabular}{|c|c|c|c|c|c|c|c|}
\hline \multicolumn{4}{|c|}{ Go to church or religious institution } & \multicolumn{4}{|c|}{ Cultural events (concerts, theater, lectures) } \\
\hline Answer & Freq. & Percent & Cum. & Answer & Freq. & Percent & Cum. \\
\hline$[-1]$ No Answer & $1,673.19$ & 0.46 & 0.46 & {$[-1]$ No Answer } & $1,974.03$ & 0.54 & 0.54 \\
\hline [1] Every day & $13,245.93$ & 3.65 & 4.11 & [1] Every day & $10,178.24$ & 2.8 & 3.35 \\
\hline [2] Every week & $17,774.41$ & 4.9 & 9 & [2] Every week & $26,486.73$ & 7.3 & 10.64 \\
\hline [3] Every month & $43,464.11$ & 11.97 & 20.98 & [3] Every month & $85,108.55$ & 23.44 & 34.08 \\
\hline [4] Less Frequently & $84,280.77$ & 23.21 & 44.19 & [4] Less Frequently & $87,583.15$ & 24.12 & 58.21 \\
\hline [5] Never & $30,049.32$ & 8.28 & 52.47 & [5] Never & $27,421.27$ & 7.55 & 65.76 \\
\hline not observed & $172,585.28$ & 47.53 & 100 & not observed & $124,321.03$ & 34.24 & 100 \\
\hline Total & 363,073 & 100 & & Total & 363,073 & 100 & \\
\hline \multicolumn{4}{|c|}{ Cinema, pop concerts, dance, sport events } & \multicolumn{4}{|c|}{ Participate in sports } \\
\hline Answer & Freq. & Percent & Cum. & Answer & Freq. & Percent & Cum. \\
\hline$[-1]$ No Answer & $2,285.49$ & 0.63 & 0.63 & {$[-1]$ No Answer } & $3,226.42$ & 0.89 & 0.89 \\
\hline [1] Every day & $12,726.16$ & 3.51 & 4.13 & [1] Every day & $53,677.99$ & 14.78 & 15.67 \\
\hline [2] Every week & $30,145.76$ & 8.3 & 12.44 & [2] Every week & $27,850.02$ & 7.67 & 23.34 \\
\hline [3] Every month & $71,153.10$ & 19.6 & 32.04 & [3] Every month & $34,421.52$ & 9.48 & 32.82 \\
\hline [4] Less Frequently & $83,926.06$ & 23.12 & 55.15 & [4] Less Frequently & $94,412.28$ & 26 & 58.83 \\
\hline [5] Never & $26,472.51$ & 7.29 & 62.44 & [5] Never & $25,163.74$ & 6.93 & 65.76 \\
\hline not observed & $136,363.93$ & 37.56 & 100 & not observed & $124,321.03$ & 34.24 & 100 \\
\hline Total & 363,073 & 100 & & Total & 363,073 & 100 & \\
\hline \multicolumn{4}{|c|}{ Visit firends, relatives, or neighbors } & \multicolumn{4}{|c|}{ Help out friends, relatives, or neighbors } \\
\hline Answer & Freq. & Percent & Cum. & Answer & Freq. & Percent & Cum. \\
\hline$[-1]$ No Answer & $1,249.44$ & 0.34 & 0.34 & {$[-1]$ No Answer } & $1,849.72$ & 0.51 & 0.51 \\
\hline [1] Every day & $70,305.45$ & 19.36 & 19.71 & [1] Every day & $20,766.50$ & 5.72 & 6.23 \\
\hline [2] Every week & $63,095.45$ & 17.38 & 37.09 & [2] Every week & $51,622.22$ & 14.22 & 20.45 \\
\hline [3] Every month & $37,463.24$ & 10.32 & 47.4 & [3] Every month & $77,657.99$ & 21.39 & 41.84 \\
\hline [4] Less Frequently & $5,528.37$ & 1.52 & 48.93 & [4] Less Frequently & $25,745.52$ & 7.09 & 48.93 \\
\hline not observed & $185,431.04$ & 51.07 & 100 & not observed & $185,431.04$ & 51.07 & 100 \\
\hline Total & 363,073 & 100 & & Total & 363,073 & 100 & \\
\hline \multicolumn{4}{|c|}{ Volunteer work } & \multicolumn{4}{|c|}{ In actions groups, political parties, local gov } \\
\hline Answer & Freq. & Percent & Cum. & Answer & Freq. & Percent & Cum. \\
\hline$[-1]$ No Answer & $3,068.02$ & 0.85 & 0.85 & {$[-1]$ No Answer } & $3,334.45$ & 0.92 & 0.92 \\
\hline [1] Every day & $22,899.73$ & 6.31 & 7.15 & [1] Every day & $12,585.66$ & 3.47 & 4.38 \\
\hline [2] Every week & $16,821.25$ & 4.63 & 11.79 & [2] Every week & $3,804.68$ & 1.05 & 5.43 \\
\hline [3] Every month & $24,909.77$ & 6.86 & 18.65 & [3] Every month & $12,253.39$ & 3.37 & 8.81 \\
\hline [4] Less Frequently & $125,660.27$ & 34.61 & 53.26 & [4] Less Frequently & $154,204.49$ & 42.47 & 51.28 \\
\hline [5] Never & $45,392.93$ & 12.5 & 65.76 & [5] Never & $52,569.29$ & 14.48 & 65.76 \\
\hline not observed & $124,321.03$ & 34.24 & 100 & not observed & $124,321.03$ & 34.24 & 100 \\
\hline Total & 363,073 & 100 & & Total & 363,073 & 100 & \\
\hline
\end{tabular}

Table 1: Distributions of answers to item measuring sociability indicators for the whole SOEP. 


\section{Results}

\subsection{The SWB regression}

We estimate equation (2) using OLS with individual fixed effects under the baseline specification described in the previous section. Table 2 reports the estimates.

A first finding is that household income is positively correlated with SWB. The coefficients of reference income and lagged income are both highly statistically significant and their sign is consistent with the presence, respectively, of social comparisons and hedonic adaptation. However, while the coefficient of absolute income is about 0.42 , the sum of the coefficients for the reference and lagged income is about -0.35 (being about -0.27 and -0.08 , respectively), which amounts to more than four fifths of the coefficient of absolute income. According to these numbers rising income goes with higher life satisfaction. To understand the magnitude of this effect is sufficient to look at the net change implied by a rise in income of 500 euros, starting from an income of 200 euros per month. Passing from 200 to 700 euros is associated with a gain in life satisfaction of 0.093 ; from 700 to 1200 the gain is 0.04 ; from 1200 to 1700 the gain is 0.026; from 1700 to 2200 the gain is 0.019 ; from 2200 to 2700 the gain is 0.015 ; from 2700 to 3200 the gain is 0.013 ; from 3200 to 3700 the gain is 0.011 , and so forth. These are definitely non-negligible numbers.

Summing up, these results are consistent with the idea that both social comparisons and adaptation are at work, with the former having a larger role. However, these results are not consistent with the idea that the joint effect of social comparisons and adaptation wipe out the whole positive effect of rising income. This is in line with what found by a series of papers exploring the potential role of social comparisons such as Luttmer (2005) and Bartolini et al. (2011) for the US, Blanchflower and Oswald (2004b) for both US and UK, and Ferrer-iCarbonell (2005) for Germany.

Present findings are very close to those obtained by Layard and Nickell (2009) who estimate a similar SWB equation using the West German sub-sample of the SOEP, considering a longer period. In line with our results, Layard and Nickell (2009) find that both lagged and reference income are negatively correlated with SWB, with reference income playing a larger role. The main difference with our results arises when considering the benefits from income growth: the estimates by Layard and Nickell (2009) suggest that benefits of income growth are 
OLS with individual fixed effects, Germany in 1994-2007

\begin{tabular}{lcl}
\hline \hline Dependent variable: Life satisfaction (1-10) & Coefficient & $\mathrm{p}-\mathrm{value}$ \\
\hline married & 0.0968 & {$[0.024]^{* *}$} \\
separated & -0.3320 & {$[0.000]^{* * *}$} \\
divorced & -0.0014 & {$[0.983]$} \\
widowed & -0.2110 & {$[0.009]^{* * *}$} \\
age & -0.0211 & {$[0.000]^{* * *}$} \\
age squared & -0.0003 & {$[0.000]^{* * *}$} \\
household size & -0.1250 & {$[0.000]^{* * *}$} \\
1 child & 0.1280 & {$[0.002]^{* * *}$} \\
2 children & 0.1550 & {$[0.004]^{* * *}$} \\
3 or more children & 0.3670 & {$[0.000]^{* * *}$} \\
years of education & 0.0095 & {$[0.233]$} \\
living with parents when 16 & -0.0009 & {$[0.983]$} \\
log of monthly household income & 0.4210 & {$[0.000]^{* * *}$} \\
log of reference income & -0.2720 & {$[0.001]^{* * *}$} \\
log of monthly household income 3 years before & -0.0751 & {$[0.000]^{* * *}$} \\
at least monthly attending religious events & 0.0766 & {$[0.000]^{* * *}$} \\
at least monthly attending cultural events & 0.1280 & {$[0.000]^{* * *}$} \\
at least monthly attending cinema, pop concerts and similar & 0.0276 & {$[0.183]$} \\
at least monthly actively participating in sports & 0.0671 & {$[0.000]^{* * *}$} \\
at least monthly volunteering & -0.0200 & {$[0.290]$} \\
at least monthly participating in social gatherings & 0.1900 & {$[0.000]^{* * *}$} \\
at least monthly helping out friends & 0.0733 & {$[0.000]^{* * *}$} \\
at least monthly participating in local political activities & -0.0160 & {$[0.533]$} \\
unemployed & -0.5540 & {$[0.000]^{* * *}$} \\
student & 0.0214 & {$[0.679]$} \\
not working for other reasons & -0.0446 & {$[0.147]$} \\
retired & 0.0495 & {$[0.240]$} \\
doing military or civil service & -0.2430 & {$[0.055]^{* *}$} \\
living in West Germany & -0.1590 & {$[0.779]$} \\
Year dummies & yes & $\cdot$ \\
Lander dummies & yes & {[} \\
constant & 8.144 & {$[0.000]^{* * *}$} \\
\hline Number of observations & 59527 & \\
Overall R-square & 0.03 & \\
F-stat & 35.34 & $\mathrm{p}<0.000$ \\
\hline \hline
\end{tabular}

Table 2: OLS regression with robust standard errors and individual fixed effects. The omitted categories are: employed, living in East Germany, without children, and single. Year and Lander dummies included. First column shows the coefficients from the regression $\left({ }^{*}\right.$ means significant at $10 \%,{ }^{* *}$ means significant at $5 \%,{ }^{* * *}$ means significant at $1 \%$.). The last column reports the p-value.

fully offset by past and reference income. We suspect that this different outcome is due to the fact that they use a rough measure of reference income, namely average national household 
income.

The findings by Di Tella et al. (2007) and Di Tella and MacCulloch (2008b) suggest that, at least for certain social groups, income adaptation is complete after about five years. This is partly in contrast with our findings and with those by Layard and Nickell (2009) as we both find only a secondary role for income adaptation. We suspect that the main driver of this difference is the absence of a reference income variable with the consequence that past income might be capturing part of the reference income effects, hence increasing its relevance to SWB. Indeed in the case of Di Tella et al. (2007) social standing is measured by means of the OPS index, while in Di Tella and MacCulloch (2008b) social standing is totally absent. In any case, since in both papers full adaptation occurs only for certain social groups - females, leftists and employees in Di Tella et al. (2007), home-owners in Di Tella and MacCulloch (2008b) on average full adaptation fails to happen, which is consistent with our findings and those in Layard and Nickell (2009).

A second relevant finding is that social capital seems to matter a great deal, at least for what regards the components captured by the available indicators. More precisely, although being involved in volunteering and local political activities does not seem to be correlated with higher SWB, attending cultural or religious events, participating in social gatherings, playing sports, and helping friends are correlated with SWB. In particular, participation in social gatherings shows the highest correlation. In order to test if the applied indicators of social capital are capturing the same latent variable, we run a principal component analysis. Results are reported in table 12 in the Appendix. Seven estimated components capture between .16 and .06 of total variation, while the first one captures about .29 . To obtain at least .8 of total variation we need at least six components, while to obtain .95 we need all eight components. So we tend to exclude the eight indicators are capturing the same latent variable.

To have an idea of the potential role of social capital a few numerical examples can be useful. Consider two hypothetical individuals, A and B, with identical characteristics but for the fact that A has all social capital indicators equal to zero, while B participates in social gatherings, helps friends, attends to both religious and cultural events, and plays sports at least once a month. In other words, all the social capital indicators for individual B takes value 1 . In such a case, the life satisfaction of individual B is higher than the life satisfaction of individual A of about .65. To have an idea of the size of such a difference, we suppose that individual A 
earns 1200 euro per month and let us calculate how much additional earnings she requires for an increase in her life satisfaction of about .65, i.e., how much additional earnings individual A needs to be as much satisfied as individual B. It turns out that individual A should earn an additional 1000 euros per month - almost doubling her earnings - and this without considering adaptation and comparisons.

The estimated coefficients associated with the remaining regressors are substantially in line with what found in the SWB literature (see, e.g., Van Praag et al., 2003, Blanchflower and Oswald, 2004b, and comments therein). The only relevant exception is age which, instead of the usual U-shaped relationship with SWB, shows a concave and negative relationship, suggesting that old age is associated with a particularly low life satisfaction for Germans. To test if this result is driven by the behavior of SWB in the old age, we run an additional regression excluding people of age 65 or older. We found that the usual U-shape re-appears. This suggests that the negative and concave relationship estimated in the baseline regression is mainly due to a strongly negative and concave relationship in the very old age ${ }^{8}$ Although, as mentioned above, the relationship between age and SWB is typically found to be U-shaped 9 , our findings are not in contrast with the more recent evidence. Indeed, the U-shaped relationaship has been questioned by a series of papers pointing to sharp declines in SWB in the very old age. Charles et al. (2001), using 23-year longitudinal data from the US, find substantial declines in SWB after age 65. Gerstorf et al. (2010), using long-term longitudinal data of deceased participants in national samples from Germany, the UK, and the US, show that life satisfaction declined rapidly between three and five years prior to death. Gerstorf et al. (2010) using longitudinal data from the SOEP, indicate steep declines in well-being with impending death. Becchetti et al. (2011), using again longitudinal data from the SOEP, include dummies for all age categories and find that the relationship between age and SWB is U-shaped only up to the age of 65 , after it becoming negative and concave 10

\footnotetext{
${ }^{8}$ In order to explore different non-linear relationships between age and SWB, we run further regressions where we include not only age and age squared, but also higher order variables. We found confirmation that in the very old age the relationship is strongly negative and concave.

${ }^{9}$ See, e.g., Clark and Oswald (2006), Blanchflower and Oswald (2004a) and references therein for a full list of contributions supporting the U-shape hypothesis in economics. See instead Mroczek and Spiro (2005) for a recent contribution in the psychological literature which also supports the U-shape hypothesis. Interestingly enough, Mroczek and Spiro (2005) find that the age of minimum SWB is greater than the one typically found by economists of about twenty years (in the 60s instead of the 40s).

${ }^{10}$ See also Easterlin (2006) and Van Landeghem (2008) on this issue.
} 
A possible explanation for these different evidence on the age profile of life satisfaction is that in cross-sectional surveys, where the U-shaped relationship emerged many times, the old people who are in bad shape do not participate. Instead, in longitudinal surveys many efforts are done to have even very sick people included in the sample, and thus a decline of wellbeing in the very old age is more likely to be observed. Evidence which seems to contrast with this explanation is provided by Van Praag et al. (2003) and Ferrer-i-Carbonell (2005) where a SWB equation is estimated exploting the longitudinal structure of the SOEP and where the Ushape relationship is found. In these papers, however, the age variables are the logs of current age and current age squared so that comparisons are hard to make. A more comparable case is provided by Ferrer-i-Carbonell and Frijters (2004b), who find the U-shape in a variety of different models that use a specification of age variables similar to ours. In trying to explain the difference between their and our findings, a natural guess is that the introduction of social capital indicators alters the U-shape relationship 11 In order to test this hypothesis we run a new regression excluding sociability indicators. The negative concave relationship, however, turned out to be robust to such an exclusion.

\subsection{Prediction of SWB}

Before proceeding with our analysis, it is useful to have an idea of the evolution of SWB in the period considered. Figure 1 illustrates the path of SWB separately for East and West Germany as well as for Germany as a whole. Average SWB slightly declined between 1996 and 2007.

Using the estimates from equation (2) we attempt to predict the average variation of SWB from 1996 to 2007 for the whole Germany. We do this by calculating the variation in SWB implied by the change over the period considered in each statistically significant regressor in equation 2, except for Lander and years dummies. More precisely, the implied SWB variation is obtained as the sum of all products between the statistically significant estimated coefficients and the total variation over time of the associated regressors. Formally, we predict the SWB variation as follows:

$$
\Delta S \hat{W} B=\hat{b} \Delta \tilde{X}+\hat{c}_{1} \Delta \ln (y)+\hat{c}_{2} \Delta \ln (\bar{y})+\hat{c}_{3} \Delta \ln \left(y_{-3}\right)+\hat{d} \Delta \tilde{S C}
$$

\footnotetext{
${ }^{11}$ In this respect, Becchetti et al. (2008) do not provide any indication since they do not allow for a non-linear relationship between age and SWB.
} 
Predicting the evolution of life satisfaction in Germany, disaggregated

\begin{tabular}{|c|c|c|c|c|c|c|c|c|}
\hline \multicolumn{3}{|c|}{ Estimates of baseline regression } & \multirow[b]{2}{*}{ Mean } & \multirow[b]{2}{*}{ StDv } & \multirow[b]{2}{*}{ Mean } & \multirow[b]{2}{*}{ StDv } & \multicolumn{2}{|c|}{ Predicted } \\
\hline Variables & Coeff & p-value & & & & & $\Delta 96-07$ & $\triangle \mathbf{S W B}$ \\
\hline SWB (observed) & & & 6.885 & 1.842 & 6.816 & 1.855 & -0.069 & \\
\hline married & 0.097 & {$[0.024]^{* *}$} & 0.560 & 0.496 & 0.521 & 0.500 & -0.039 & -0.0038 \\
\hline separated & -0.332 & {$[0.000]^{* * *}$} & 0.018 & 0.132 & 0.021 & 0.143 & 0.003 & -0.0010 \\
\hline divorced & -0.001 & {$[0.983]$} & 0.071 & 0.258 & 0.094 & 0.292 & 0.023 & \\
\hline widowed & -0.211 & {$[0.009]^{* * *}$} & 0.105 & 0.306 & 0.087 & 0.282 & -0.018 & 0.0037 \\
\hline age & -0.021 & {$[0.000]^{* * *}$} & 47.183 & 18.035 & 49.025 & 18.034 & 1.842 & -0.0389 \\
\hline age squared & -0.0003 & {$[0.000]^{* * *}$} & 2551.5 & 1824.7 & 2728.7 & 1868.9 & 177.211 & -0.0503 \\
\hline household size & -0.125 & {$[0.000]^{* * *}$} & 2.590 & 1.285 & 2.439 & 1.236 & -0.151 & 0.0189 \\
\hline 1 child & 0.128 & {$[0.002]^{* * *}$} & 0.169 & 0.375 & 0.150 & 0.357 & -0.019 & -0.0024 \\
\hline 2 children & 0.155 & {$[0.004]^{* * *}$} & 0.108 & 0.311 & 0.088 & 0.283 & -0.020 & -0.0031 \\
\hline 3 or more children & 0.367 & {$[0.000]^{* * *}$} & 0.035 & 0.185 & 0.025 & 0.156 & -0.011 & -0.0039 \\
\hline years of education & 0.010 & {$[0.233]$} & 11.464 & 2.515 & 12.044 & 2.639 & 0.580 & \\
\hline with parents at 16 & -0.001 & {$[0.983]$} & 1.708 & 0.455 & 1.757 & 0.429 & 0.049 & \\
\hline log monthly income & 0.421 & {$[0.000]^{* * *}$} & 7.699 & 0.487 & 7.750 & 0.583 & 0.050 & 0.0212 \\
\hline log reference income & -0.272 & {$[0.001]^{* * *}$} & 7.815 & 0.158 & 7.867 & 0.230 & 0.053 & -0.0143 \\
\hline log income 3 years before & -0.075 & {$[0.000]^{* * *}$} & 7.627 & 0.572 & 7.645 & 0.594 & 0.018 & -0.0013 \\
\hline monthly at church & 0.077 & {$[0.000]^{* * *}$} & 0.488 & 0.500 & 0.459 & 0.498 & -0.029 & -0.0022 \\
\hline monthly at cultural events & 0.128 & {$[0.000]^{* * *}$} & 0.659 & 0.474 & 0.691 & 0.462 & 0.031 & 0.0040 \\
\hline monthly at cinema & 0.028 & {$[0.183]$} & 0.647 & 0.478 & 0.689 & 0.463 & 0.041 & \\
\hline monthly playing sport & 0.067 & {$[0.000]^{* * *}$} & 0.518 & 0.500 & 0.610 & 0.488 & 0.091 & 0.0061 \\
\hline monthly at sc & 0.190 & {$[0.000]^{* * *}$} & 0.778 & 0.416 & 0.789 & 0.408 & 0.011 & 0.0022 \\
\hline monthly help & 0.073 & {$[0.000]^{* * *}$} & 0.411 & 0.492 & 0.437 & 0.496 & 0.025 & 0.0019 \\
\hline monthly volunteering & -0.020 & {$[0.290]$} & 0.293 & 0.455 & 0.303 & 0.460 & 0.011 & \\
\hline monthly political active & -0.016 & {$[0.533]$} & 0.111 & 0.314 & 0.082 & 0.274 & -0.029 & \\
\hline unemployed & -0.554 & {$[0.000]^{* * *}$} & 0.061 & 0.239 & 0.056 & 0.231 & -0.004 & 0.0025 \\
\hline student & 0.021 & {$[0.679]$} & 0.030 & 0.171 & 0.029 & 0.167 & -0.001 & \\
\hline non working & -0.045 & {$[0.147]$} & 0.133 & 0.339 & 0.091 & 0.288 & -0.041 & \\
\hline retired & 0.050 & {$[0.240]$} & 0.177 & 0.382 & 0.206 & 0.404 & 0.028 & \\
\hline military/civil service & -0.243 & {$[0.055]^{*}$} & 0.003 & 0.054 & 0.001 & 0.030 & -0.002 & 0.0005 \\
\hline west & -0.159 & {$[0.779]$} & 0.813 & 0.390 & 0.815 & 0.388 & 0.003 & \\
\hline
\end{tabular}

Table 3: First column shows the coefficients of the baseline SWB regression $\left(^{*}\right.$ means significant at $10 \%,{ }^{* * *}$ means significant at 5\%, ${ }^{* * *}$ means significant at 1\%.). Second and third columns report, respectively, mean values of regressors in 1996 and their standard errors. Fourth and fifth columns report, respectively, mean values of regressors in 2007 and their standard errors. Sixth column reports the difference between average values of regressors in 2007 and average values in 1996. Last column reports the change in predicted probability of reporting to be "satisfied with own life" which is imputed to each regressor (it comes from the product of the values in column seven and the coefficients reported in column one). Reported numbers are relative to coefficients that are significant at least at the $10 \%$ level. 


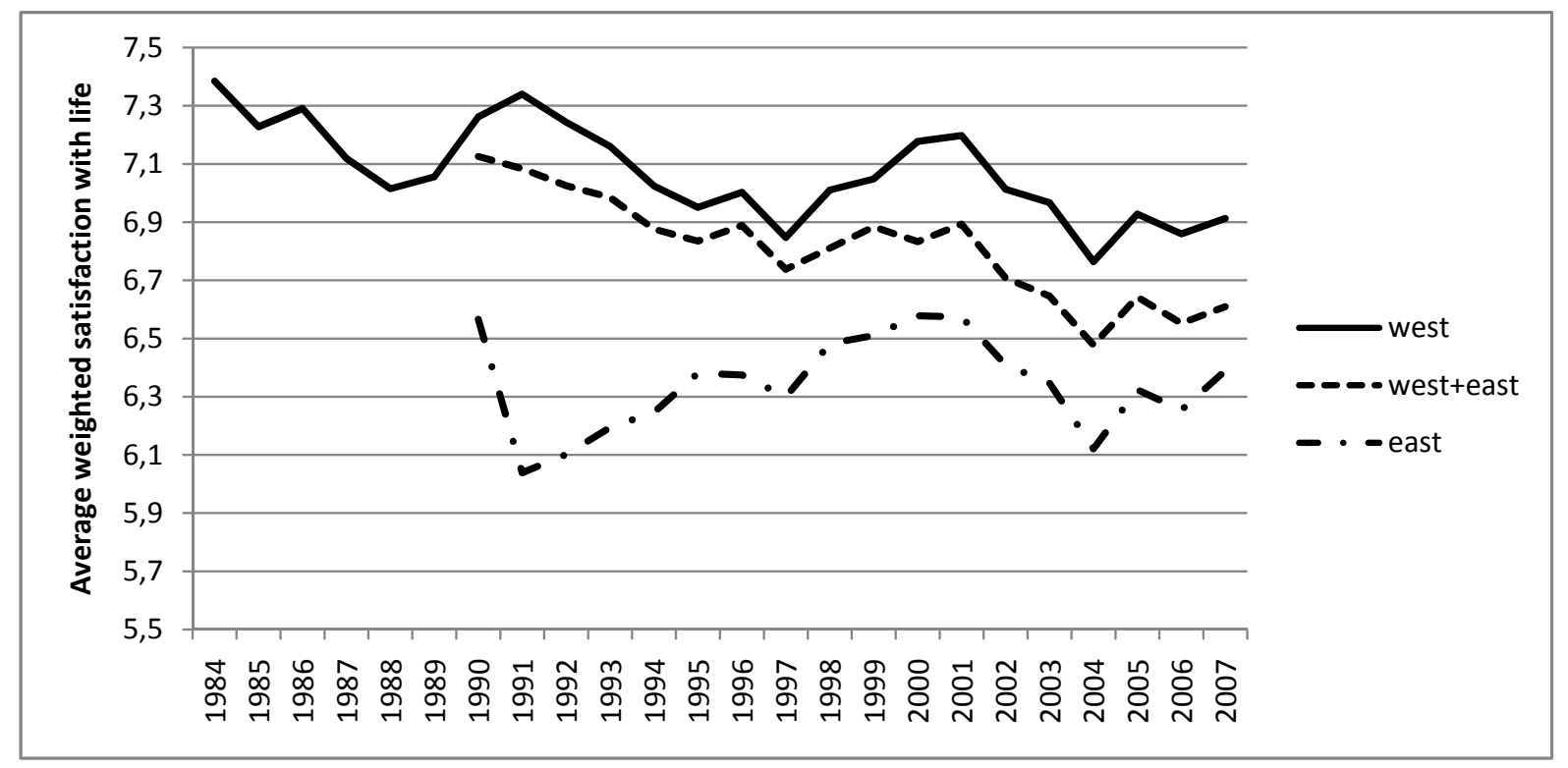

Trends of average weighted satisfaction with life for the three sub-samples: westerners (1984 - 2007); easterners (1990 - 2007) and the two sub-samples together $(1990$ - 2007). Averages have been computed using cross-sectional sampling weights (GSOEP source variable: w1110507).

Figure 1: Trends of average weighted satisfaction with life for the three sub-samples: westerners (1984 - 2007); easterners (1990 - 2007) and the two sub-samples together (1990 - 2007). Averages have been computed using cross-sectional sampling weights (SOEP source variable: w1110507).

where $\hat{b}, \hat{c}_{1}, \hat{c}_{2}, \hat{c}_{3}$ and $\hat{d}$ are the coefficients estimated from equation 2) which are statistically significant at least at the $10 \%$ level, while $\Delta \tilde{X}, \Delta \ln (y), \Delta \ln (\bar{y}), \Delta \ln \left(y_{-3}\right)$, and $\Delta \tilde{S C}$ are the variations of regressors associated with such coefficients.

We emphasize that variations of regressors are calculated using the weights provided in the SOEP in order to correct for special purpose stratifications and over-samplings. This has two consequences. First, we can attempt to predict the variation of SWB for the whole population of Germany, and not only for the sample of individuals surveyed in the SOEP. Second, our calculation is indeed a prediction and not just a decomposition technique. This point is further reinforced by the fact that, while we estimated equation (2) for the period 1994-2007, we calculate equation (3) only for the period 1996-2007. The reason is that before 1994 lagged income is not observed for the East Germany sample while in 1993 and 1995 social capital indicators are not observed at all.

Table 3 reports the predicted changes in SWB at the most disaggregated level. Before moving to more aggregated figures, a comment on the trends of significant regressors is worth doing. Married and widowed individuals seem to have decreased in number while separated 
people have increased. This suggests that the number of singles has been systematically increasing during the considered period. Not surprisingly, the average age increased of about two years while the share of household having children decreased for all categories considered. Consistently with these trends, household size decreased as well. These numbers depict an important change in the average household in Germany: older, smaller, with less children, and more often constituted by a single person. As expected, income growth has induced an increase in all income variables, i.e., absolute income, reference income, and past income. Again unsurprisingly, both unemployment and military/civil service slightly decreased.

Turning to social capital indicators we note that most of them increased between 1996 and 2007. This is especially true for participating actively in sports and attending cultural events which increased by $10 \%$ and $4 \%$, respectively. Also the remaining indicators of social capital show an upward variation of about $1-2 \%$. The only exception is participation in religious activities, with a $3 \%$ decrease.

Table 4 illustrates the predicted changes in SWB when we aggregate the regressors in six categories: marital status, age, household characteristics, income, social capital, and work status. Basically, these categories represent important life domains which are supposed to affect life satisfaction. Before commenting on each category separately, we find important to recall that small changes in SWB are typically very relevant. Indeed, SWB is a measure with an extremely low variability: it shows a standard deviation of just 1.84 on an 11-points scale . Therefore, even a $0.1 \%$ change in SWB, corresponding to an absolute change of about 0.007 , deserves careful consideration.

First of all, note that the total predicted variation is .06 , which is very close to the observed variation of .069. This is a remarkably good result. Indeed, as the analysis in Di Tella and MacCulloch (2008a) shows, applying this prediction technique can lead to figures that are distant from the observed values.

A second interesting aspect is that substantial changes in marital status predict a rather small change in SWB. This is the result of two contrasting facts: less married people and more separated people against less widowed people. By the same token, a mild change in work status predicts a small change in SWB. Here, however, there is no contrast: both less unemployment and less military/civil service predict a higher SWB.

Further, note that the increase in average age, which follows a general trend in industrial 
Predicting the trend of life satisfaction in 1996-2007, partial sums

\begin{tabular}{lccccc}
\hline \hline Variables & Coeff. & $\Delta \mathbf{9 6 - 0 7}$ & all & $\begin{array}{c}\text { Predicted } \Delta \text { SWB } \\
\text { partial sums }\end{array}$ & total \\
\hline life satisfaction (observed) & & $\mathbf{- 0 . 0 6 9}$ & & & \\
\hline married & 0.097 & -0.039 & -0.0038 & \\
separated & -0.332 & 0.003 & -0.0010 & Marital status & widowed \\
\hline age & -0.211 & -0.018 & 0.0037 & -0.001 \\
age squared & -0.021 & 1.842 & -0.0389 & Age \\
\hline household size & -0.0003 & 177.211 & -0.0503 & -0.089 \\
1 child & -0.125 & -0.151 & 0.0189 & \\
2 children & 0.128 & -0.019 & -0.0024 & Household \\
3 or more children & 0.155 & -0.020 & -0.0031 & characteristics \\
\hline log monthly income & 0.367 & -0.011 & -0.0039 & 0.010 \\
log reference income & 0.421 & 0.050 & 0.0212 & \\
log income 3 years before & -0.272 & 0.053 & -0.0143 & Income \\
\hline monthly at religious events & -0.075 & 0.018 & -0.0013 & 0.006 \\
monthly at cultural events & 0.077 & -0.029 & -0.0022 & \\
monthly playing sport & 0.067 & 0.031 & 0.0040 & \\
monthly at social gathering & 0.190 & 0.091 & 0.0061 & \\
monthly helping friends & 0.073 & 0.025 & 0.0022 & Social Capital & \\
\hline unemployed & -0.554 & -0.004 & 0.0025 & Work status & \\
military/civil service & -0.243 & -0.002 & 0.0005 & 0.003 \\
\hline \hline
\end{tabular}

Table 4: First column reports the estimated coefficient which are significant at least at $10 \%$ level. The second column reports the variation of the regressors between 1996 and 2007, properly weighted to represent German population. The third column reports the predicted change in life satisfaction associated with each regressor. The fourth column reports partial sums of predictions while last column reports the total sum variations. Observed variation of life satisfaction is displayed at the top of second the column.

countries, predicts the largest negative change in SWB. Given the negative concave relationship between age and SWB that we found in the estimates from equation (2) this is not surprising.

Turning our attention to income growth, we see that it predicts a small but not negligible increase in SWB. Notwithstanding the negative predicted change in SWB due to the growth of reference income and past income, the net prediction of income growth is positive, though small. This is consistent with the findings of Di Tella and MacCulloch (2008a) for the EU. In other words, it seems that more money goes with more SWB, although only moderately so.

A further positive change in SWB is predicted by the change in household characteristics. More precisely, the reduction in the number of children predicts a reduction in SWB which 
is more than offset by the positive change predicted by the shrinking in household size. This is consistent with what found in Blanchflower and Oswald (2004b). Our interpretation is that the reduction in household size captures the fact that a given amount of household income buys more goods and services per household member, while having less children captures a poorer relational environment in the household. If this interpretation is correct, then the actual increase in SWB predicted by income growth is greater than the estimated value of .006 . However, it would not be substantially greater because the change in SWB predicted by the change in household characteristics is about 0.10 and only a fraction of it can be reasonably interpreted as the result of an indirect change in income. The reason is that such an indirect income growth is not controlled for hedonic adaptation and social comparisons.

Finally, social capital provides the largest positive predicted variation of SWB. This suggests an important role for social capital, at least in its relational component. Again, this is consistent with Bartolini et al. (2011) who find that a large portion of the US change in SWB between 1975 and 2004 is predicted by the decline in social capital.

Summing up, the slight decrease in SWB that took place in Germany between 1996 and 2007 is well predicted by the following contrasting trends: worsening of marital status with almost no change in SWB, increasing social capital going with a moderate increase in SWB, income growth going with a slight increase in SWB, shrinking of family size going with a slight increase of SWB, ageing of the population going with a substantial decrease in SWB and finally an improvement in work status which goes with a very small increas in SWB.

\subsection{Prediction or Decomposition?}

We emphasise that our prediction of the average well-being of Germans is not the outcome of a simple decomposition of variation. Indeed, similarities between techniques for prediction and for decomposition may be misleading suggesting that present analysis is just a decomposition. This is not the case for at least three important reasons.

In the first place, we do not use all estimated coefficients, but only those that turn out to be statistically significant at least at $10 \%$ level. Moreover, we also discard statistical significant coefficients of regional and year dummies.

In the second place, we estimate our baseline regression without weights while we carry out our predictions applying weights. This means that the variation used to estimate our baseline 
regression is not the same that we apply to obtain our predictions.

Finally, as shown by Di Tella and MacCulloch (2008a), our approach can lead to predictions that are far away from observed values. In particular, adding regressors with significant coefficients does not necessarily improve the precision of the prediction

\section{Robustness checks}

In this section we explore the robustness of our findings by varying the specification of the baseline equation and, where necessary, adjusting predictions accordingly.

\subsection{Alternative specifications of adaptation}

As anticipated in section 2.4, we re-estimated equation (2) using different year lags for the household income variable. In particular, we re-estimate (2) with $k=1,2,4,5,6,7$, and 8. The estimates are reported in table 5. In each regression we include a different specification of lagged income. The numbers reported in the top row of table 5 identify the regressions and indicate the number of years used to calculate lagged household income. For the sake of comparison, we report also the estimation with $k=3$.

Overall, previous results are substantially confirmed. Almost all coefficients for nonincome variables turn out to be extremely stable to this change in specification. One exception is the coefficient associated with the indicator "at least monthly attending cinema, pop concerts, etc" which, by increasing the lag of past income, becomes smaller and eventually statistically insignificant. This may be mainly due to the fact that with a longer lag we lose observations on young people which are more likely to go and benefit from such activities. Another exception concerns people in military/civil service. This also may be driven by the progressive exclusion of young people. Further investigation on descriptives confirms these hypothesis 12

\footnotetext{
${ }^{12}$ Please refer to table 10 on page 33 in the Appendix for more details.
} 


\section{Varying the lag of past household income: East and West Germany}

\begin{tabular}{|c|c|c|c|c|c|c|c|}
\hline Variables & $\begin{array}{c}(1) \\
\text { Coeff. }\end{array}$ & $\begin{array}{l}(2) \\
\text { Coeff. }\end{array}$ & $\begin{array}{c}\begin{array}{c}(3) \\
\text { Coeff. }\end{array}\end{array}$ & $\begin{array}{l}\text { (4) } \\
\text { Coeff. }\end{array}$ & $\begin{array}{l}\begin{array}{c}\text { (5) } \\
\text { Coeff. }\end{array}\end{array}$ & $\begin{array}{l}(6) \\
\text { Coeff. }\end{array}$ & 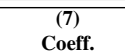 \\
\hline married & & & & 0.0989 ** & & & \\
\hline separated & $-0.333 * * *$ & $-0.336 * * * *$ & $-0.332 * * *$ & $-0.334 * * *$ & $-0.328 * * *$ & $-0.373 * * *$ & $-0.337 * * *$ \\
\hline divorced & 0.0410 & 0.0235 & -0.00142 & 0.000190 & 0.0230 & -0.0130 & -0.00196 \\
\hline widowed & $-0.190 * *$ & $-0.157 * *$ & $-0.211^{* * * *}$ & $-0.192 * *$ & $-0.219^{* * * *}$ & $-0.292 * * * *$ & $-0.253 * * *$ \\
\hline & $-0.0223 * * *$ & $-0.0231 * * *$ & $-0.0211^{* * *}$ & $-0.0207^{* * * *}$ & $-0.0222 * * * *$ & $-0.0199 * * *$ & $-0.0194 * * * *$ \\
\hline age2 & $-0.000268 * * * *$ & $-0.000253^{* * * *}$ & $-0.000284 * * *$ & $-0.000289^{* * *}$ & $-0.000277^{* * * *}$ & $-0.000289 * * *$ & $-0.000292 * * *$ \\
\hline household size & $-0.134 * * *$ & $-0.133 * * *$ & $-0.125 * * * *$ & $-0.124 * * * *$ & $-0.110^{* * * *}$ & $-0.111 * * * *$ & -0.121 *** \\
\hline 1 child & $0.144^{* * * * *}$ & $0.144^{* * * *}$ & $0.128 * * * *$ & $0.144 * * *$ & $0.114^{* *}$ & $0.122 * *$ & $0.126^{* * * *}$ \\
\hline 2 children & $0.183^{* * * *}$ & $0.180^{* * * *}$ & $0.155^{* * * *}$ & $0.176^{* * * *}$ & $0.121^{* *} *$ & $0.118 * *$ & $0.102 *$ \\
\hline 3 or more children & $0.401^{* * * *}$ & $0.384^{* * * * *}$ & $0.367^{* * * *}$ & $0.381 * * *$ & $0.312^{* * * * *}$ & $0.317 * * *$ & $0.326^{* * * *}$ \\
\hline $\begin{array}{l}\text { years of education } \\
\text { Jivino with narents when } 16\end{array}$ & $\begin{array}{l}0.00593 \\
0.00864\end{array}$ & 0.00737 & 0.00954 & 0.00962 & 0.00977 & 0.00597 & 0.00639 \\
\hline $\begin{array}{l}\text { living with parents when } 16 \\
\text { log of monthy hopsehold }\end{array}$ & 0.00864 & 0.0119 & -0.000920 & 0.0179 & -0.00287 & 0.00499 & -0.00487 \\
\hline & $0.442^{* * * *}$ & $0.435^{* * * *}$ & $0.421^{* * *}$ & $0.405^{* * * *}$ & $0.380^{* * * * *}$ & $0.365^{* * * *}$ & $0.382 * * *$ \\
\hline $\begin{array}{l}\text { log of reference eincome } \\
\log \text { of monthly household income } 1 \text { year before }\end{array}$ & $-0.217^{* * * *}$ & $-0.227^{* * * *}$ & $-0.272^{* * * *}$ & $-0.243^{* * * *}$ & $-0.226^{* * *}$ & $-0.235^{* * * *}$ & $-0.211^{* *}$ \\
\hline $\begin{array}{l}\text { log of monthly household income } 2 \text { year before } \\
\log \text { of }\end{array}$ & & $-0.0434 * *$ & & & & & \\
\hline log of monthly household income 3 year before & & & $-0.0751 * * *$ & & & & \\
\hline log of monthly household income 4 year before & & & & $-0.0578^{* * * *}$ & & & \\
\hline log of monthly household income 5 year before & & & & & $-0.0727 * * * *$ & & \\
\hline log of monthly household income 6 year before & & & & & & $-0.0761^{* * *}$ & \\
\hline log of monthly household income 7 year before & & & & & & & $-0.0424 * *$ \\
\hline at least monthly attending religious events & $0.0924 * * *$ & $0.0964 * * * *$ & $0.0766^{* * * *}$ & $0.0697 * * *$ & $0.0718 * * *$ & $0.0733 * * *$ & $0.0697 * * * *$ \\
\hline at least monthly attending cultural events & $0.125 * * *$ & $0.125 * * *$ & $0.128^{* * * *}$ & $0.129^{* * * *}$ & $0.132 * * *$ & $0.140^{* * * *}$ & $0.137^{* * * *}$ \\
\hline at least monthly attending cinema, pop concerts, etc & $0.0352 *$ & $0.0354 *$ & 0.0276 & 0.0265 & 0.0240 & 0.0123 & 0.00747 \\
\hline at least monthly actively participating in sports & $0.0767 * * *$ & $0.0766^{* * * *}$ & 0.0671 **** & 0.0716 *** & $0.0771 * * *$ & $0.0780 * * *$ & $0.0861^{* * * * *}$ \\
\hline at least monthly volunteering. & $0.179 * * *$ & $0.183 * * *$ & $0.190^{* * * *}$ & $0.186 * * * *$ & $0.191 * * * *$ & $0.183 * * * *$ & $0.193 * * *$ \\
\hline at least monthly participating in social gatherings & $0.0628 * * * *$ & $0.0628 * * * *$ & $0.0733^{* * * * *}$ & 0.0747 **** & $0.0757^{* * * *}$ & $0.0830^{* * * * *}$ & $0.0889^{* * * * *}$ \\
\hline at least monthly helping out friends & -0.0111 & -0.00624 & -0.0200 & -0.0125 & -0.0135 & -0.00492 & -0.00828 \\
\hline at least monthly participating in local political activities & -0.0264 & -0.0269 & -0.0160 & -0.0164 & -0.0202 & -0.0224 & -0.0257 \\
\hline unemployed & $-0.586^{* * * * * *}$ & $-0.593^{* * * * *}$ & $-0.554^{* * * *}$ & $-0.566^{* * * *}$ & $-0.547 * * * *$ & $-0.548^{* * * *}$ & $-0.560^{* * *}$ \\
\hline student & 0.0315 & 0.0438 & 0.0214 & 0.0170 & 0.0283 & 0.0304 & 0.0722 \\
\hline $\begin{array}{l}\text { not working for other reasons } \\
\text { retired }\end{array}$ & -0.0362 & -0.0427 & $\begin{array}{l}-0.0446 \\
0.0995\end{array}$ & $\begin{array}{l}-0.0405 \\
0.0507\end{array}$ & -0.0435 & -0.0404 & -0.0459 \\
\hline $\begin{array}{l}\text { retired } \\
\text { doing military or civil serv }\end{array}$ & $\begin{array}{l}0.0567 \\
-0.219 *\end{array}$ & $\begin{array}{c}0.0442 \\
-0.23 * *\end{array}$ & $\begin{array}{c}0.0495 \\
-0.243 *\end{array}$ & 0.0507 & 0.0273 & 0.0159 & 0.0207 \\
\hline $\begin{array}{l}\text { dong milltary or civil service } \\
\text { living in West Germany }\end{array}$ & $\begin{array}{l}-0.219 * \\
-0.190\end{array}$ & $\begin{array}{l}-0.243 * 3 \\
-0.194\end{array}$ & 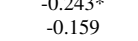 & $\begin{array}{l}-0.219 * \\
-0.192\end{array}$ & $\begin{array}{l}-0.244^{*} \\
-0.198\end{array}$ & $\begin{array}{l}-0.149 \\
-0.149\end{array}$ & $\begin{array}{l}-0.164 \\
-0.372\end{array}$ \\
\hline Year dummies & yes & yes & yes & yes & yes & & \\
\hline Lander dummies & yes & yes & yes & yes & yes & yes & yes \\
\hline constant & $7.265 * * *$ & $7.404 * * *$ & $8.144 * * *$ & $7.871^{* * * *}$ & $8.114^{* * * *}$ & 8.241 *** & $7.914 * * *$ \\
\hline number of $\mathrm{o}$ & 64999 & 64054 & 59527 & 58560 & 54338 & 50221 & 49412 \\
\hline $\mathrm{R} 2$ overall & 0.0317 & 0.0325 & 0.0273 & 0.0260 & 0.0251 & 0.0258 & 0.0261 \\
\hline & 37.49 & 36.58 & 35.34 & 34.56 & 32.33 & 30.01 & 29.62 \\
\hline prob $>F$ & 0.000 & 0.000 & 0.000 & 0.000 & 0.000 & 0.000 & 0.000 \\
\hline
\end{tabular}

Table 5: OLS regression with robust standard errors and individual fixed effects. The omitted categories are: employed, living in East Germany, without children, and single. Year and Lander dummies included. Column from (1) to (7) report estimates for differente lags of past income, repsectively, from 1 to 7 . Colum (3) replicates baseline results. (* means significant at $10 \%,{ }^{* *}$ means significant at $5 \%,{ }^{* * *}$ means significant at $1 \%$.) 
Turning our attention to the coefficients of income variables, we stress that those associated with absolute income and reference income show a remarkable robustness to changes in the lag of past income. The coefficient of reference income is substantially invariant while the coefficient of absolute income slightly decreases in the length of the lag. However, these differences are neither statistically nor economically significant.

The coefficients of lagged income show some variability but, with the exclusion of the 1year lag, all have the expected sign and roughly a similar magnitude. The coefficient of lagged income obtained in the regression with 1-year lag of past income is not statistically significant. However, its magnitude is in line with other estimates.

Summing up, this check supports the robustness of the baseline estimation of equation 2 .

\subsection{West Germany between 1988 and 2007}

In a recent article, Easterlin and Angelescu (2009) pointed out that the discrepancy between economic growth and the variation of subjective well-being holds in the long run. In other words, the period we are focusing on in present analysis might be considered too short for the paradox to apply. However, we repeated our analysis adopting a larger time span ranging from 1988 to 2007 . Unfortunately, this choice has some shortcomings. The first one is that, as pointed out in section 3 , the restrictions imposed by the availability of variables allow to focus on the West German sample only. The second one is that we have to drop the social capital indicator about religious activities. This is because the question about religious activities has been asked since 1991 only.

Estimates for West Germany turn out to be rather similar to those of the baseline regression, hence supporting our results, see tab. 6. Social capital indicators have coefficients that are remarkably similar to those estimated for equation (2). The only difference is that in this case the coefficient of the indicator about participating to popular events turns out to be statistically significant, with magnitude similar to that of participating to cultural events.

The only remaining differences which are worth mentioning come from work status and income variables. Unemployment is still the most important among work status variables, but now, in the place of civil/military service, results suggest that being retired and not working for other reasons are important. For what concerns income, we observe coefficients of smaller size (in absolute value). In particular, reference income is sensibly smaller with the result that 
OLS with individual fixed effects, West Germany in 1988-2007

\begin{tabular}{lcc}
\hline \hline Dependent variable: Life satisfaction (1-10) & Coefficient & p-value \\
\hline married & 0.109 & {$[0.001]^{* * *}$} \\
separated & -0.460 & {$[0.000]^{* * *}$} \\
divorced & -0.034 & {$[0.560]$} \\
widowed & -0.337 & {$[0.000]^{* * *}$} \\
age & -0.022 & {$[0.059]^{* * *}$} \\
age squared & 0.000 & {$[0.059]^{*}$} \\
household size & -0.123 & {$[0.000]^{* * *}$} \\
1 child & 0.132 & {$[0.001]^{* * *}$} \\
2 children & 0.170 & {$[0.001]^{* * *}$} \\
3 or more children & 0.379 & {$[0.000]^{* * *}$} \\
years of education & 0.001 & {$[0.980]$} \\
living with parents when 16 & -0.002 & {$[0.962]$} \\
log of monthly household income & 0.393 & {$[0.000]^{* * *}$} \\
log of reference income & -0.149 & {$[0.063]^{*}$} \\
log of monthly household income 3 years before & -0.033 & {$[0.067]^{*}$} \\
at least monthly attending cultural events & 0.103 & {$[0.000]^{* * *}$} \\
at least monthly attending cinema, pop concerts and similar & 0.063 & {$[0.001]^{* * *}$} \\
at least monthly actively participating in sports & 0.068 & {$[0.000]^{* * *}$} \\
at least monthly volunteering & -0.005 & {$[0.767]$} \\
at least monthly participating in social gatherings & 0.221 & {$[0.000]^{* * *}$} \\
at least monthly helping out friends & 0.071 & {$[0.000]^{* * *}$} \\
at least monthly participating in local political activities & -0.018 & {$[0.475]$} \\
unemployed & -0.571 & {$[0.000]^{* * *}$} \\
student & 0.065 & {$[0.163]^{*}$} \\
not working for other reasons & -0.075 & {$[0.006]^{* * *}$} \\
retired & 0.015 & {$[0.717]$} \\
doing military or civil service & -0.272 & {$[0.047]^{* *}$} \\
Year dummies & yes & $\cdot$ \\
Lander dummies (West Germany) & yes & $\cdot$ \\
constant & 6.559 & {$[0.000]^{* * *}$} \\
\hline Number of observations & 80337 & \\
Overall R-square & 0.03 & \\
F-stat & 44.410 & $\mathrm{p}<0.000$ \\
\hline \hline
\end{tabular}

Table 6: OLS regression with robust standard errors and individual fixed effects. The omitted categories are: employed, without children, and single. Year and Western Lander dummies included. First column shows the coefficients from the regression $\left({ }^{*}\right.$ means significant at $10 \%,{ }^{* *}$ means significant at $5 \%,{ }^{* * *}$ means significant at $1 \%$.). The last column reports the p-value.

the overall contribution of income growth to SWB might be greater than what observed in our baseline estimation. Indeed, the sum of the coefficients of reference income and past income is only about one half of the coefficient of absolute income, while in our baseline regression they sum up to about four fifths of absolute income. 
West Germany: Predicting the trend of life satisfaction in 1988-2007

\begin{tabular}{lrrrcc}
\hline \hline Variables & Coeff. & \multicolumn{1}{c}{$\Delta \mathbf{8 8 - 0 7}$} & all & $\begin{array}{c}\text { Predicted } \Delta \text { SWB } \\
\text { partial sums }\end{array}$ & total \\
\hline life satisfaction (observed) & & $\mathbf{- 0 . 1 3 0}$ & & \\
\hline married & 0.127 & -0.033 & -0.0036 & \\
separated & -0.460 & 0.002 & -0.0012 & Marital status & \\
widowed & -0.337 & 0.001 & -0.0002 & -0.005 \\
\hline age & -0.022 & 4.964 & -0.1102 & Age \\
age squared & -0.0003 & 451.431 & -0.0479 & -0.158 \\
\hline household size & -0.123 & -0.333 & 0.0410 & \\
1 child & 0.132 & -0.061 & -0.0080 & Household \\
2 children & 0.170 & 0.004 & 0.0007 & characteristics \\
3 or more children & 0.379 & -0.001 & -0.0004 & 0.033 \\
\hline log monthly income & 0.393 & 0.039 & 0.0154 & \\
log reference income & -0.149 & 0.090 & -0.0133 & Income \\
log income 3 years before & -0.033 & 0.147 & -0.049 & -0.003 \\
\hline monthly at culture events & 0.103 & 0.134 & 0.0138 & \\
monthly at cinema & 0.063 & 0.118 & 0.0075 & \\
monthly sport activities & 0.069 & 0.174 & 0.0119 & \\
monthly at social gathering & 0.221 & 0.033 & 0.0074 & Social Capital & \\
monthly helping friends & 0.071 & 0.137 & 0.097 & 0.051 \\
\hline unemployed & -0.571 & -0.001 & 0.0007 & Work status \\
not working formother reasons & -0.075 & -0.087 & -0.0065 & \\
doing military or civil service & -0.272 & -0.006 & 0.0017 & 0.009 \\
\hline \hline
\end{tabular}

Table 7: First column reports the estimated coefficient which are significant at least at $10 \%$ level. Second column reports the variation of the regression between 1988 and 2007, properly weighted to represent West German population. Third column reported the predicted change in life satisfaction associated with each regressor. Fourth column reports partial sums of predictions while last column report the total sum. Observed variation of life satisfaction is displayed at the top of second column.

Since we changed both sample and time period, calculating again predicted changes of SWB is a good robustness check for our previous findings. We report this check in table 7. In the considered period, the SWB of West Germans decreased substantially more - almost twice as much - than Germany's average SWB during 1996-2007. Our estimates predict about one half of the observed decrease. This is a good enough prediction, especially in the light of the fact that we miss the indicator for religious activities that, as shown in our baseline predictions, is positively related to SWB and has been decreasing over the period considered.

Turning our attention to marital status, age, and household characteristics, we see that, despite some differences, our results are substantially in line with what seen for the baseline 
predictions. An interesting difference is that the change in household characteristics predicts a larger increase in SWB. Arguably, this is due to the fact that during the considered period Western Germans experienced a more marked change in household characteristics. A similar argument applies to the slightly more negative prediction due to marital status.

Coming to income variables, the net prediction is negative. This is due to the fact that reference income grew substantially more than absolute income. Further investigation suggests that this is a result of a change in reference groups which progressively becomes composed of higher income households.

Once more, social capital indicators come out as the main predictors of a positive change in SWB. However, in this case the predicted change is greater. One reason is certainly the absence of the indicator of participation to religious activities. Another reason is that Western Germans has been experiencing a more intense rise in relational activities than Eastern Germans.

Finally, the prediction associated with work status variables does not appear to deserve any special comment.

\subsection{Lagged and average social capital}

One potential issue in our baseline estimation of equation (2) is that social capital indicators may be endogenous to SWB. We stress that such a potential endogeneity problem does not undermine our predictions. The co-movements that we document do not hinge on a causal interpretation. However, we provide some evidence in favor of the hypothesis that social capital affects subjective well-being. In particular, we run two robustness checks using lagged and average values of social capital, respectively. In the first case, we investigate an alternative specification of (2) in which we replace current individual-level social capital indicators with 1-year lag. Formally, we estimate

$$
S W B_{i, t}=\alpha+\beta_{1} \cdot X_{i, t}^{d}+\gamma_{1} \cdot \ln \left(y_{i, t}\right)+\gamma_{2} \cdot \ln \left(\bar{y}_{i, t}\right)+\gamma_{3} \cdot \ln \left(y_{i, t-k}\right)+\delta \cdot S C_{i, t-1}+e_{i, t}
$$

where the only difference with respect to equation (2) is represented by the index of $S C_{i, t-1}$ which stands for a 1-year lag of the social capital indicators.

Estimates are reported in table 8 and show a remarkable invariance with respect to our baseline regression. The only relevant difference is that helping out friends becomes insignifi- 
Lagged social capital indicators: East and West Germany in 1994-2007

\begin{tabular}{lcc}
\hline Dependent variable: Life satisfaction (1-10) & Coeff & p-value \\
\hline \hline married & 0.058 & {$[0.218]$} \\
separated & -0.239 & {$[0.007]^{* * *}$} \\
divorced & -0.048 & {$[0.478]$} \\
widowed & -0.297 & {$[0.001]^{* * *}$} \\
age & -0.014 & {$[0.050]^{* *}$} \\
age squared & -0.0004 & {$[0.000]^{* * *}$} \\
household size & -0.095 & {$[0.000]^{* * *}$} \\
1 child & 0.077 & {$[0.097]^{*}$} \\
2 children & 0.100 & {$[0.084]^{*}$} \\
3 or more children & 0.149 & {$[0.057]^{*}$} \\
years of education & 0.025 & {$[0.005]^{* * *}$} \\
living with parents when 16 & -0.063 & {$[0.174]$} \\
log of monthly household income & 0.393 & {$[0.000]^{* * *}$} \\
log of reference income & -0.116 & {$[0.146]$} \\
log of monthly household income 3 years before & -0.063 & {$[0.003]^{* * *}$} \\
at least monthly at church 1 year before & 0.044 & {$[0.052]^{*}$} \\
at least monthly at cultural events 1 year before & 0.042 & {$[0.033]^{* *}$} \\
at least monthly to cinema, pop concerts, etc. 1 year before & -0.001 & {$[0.966]$} \\
at least monthly participating in sports 1 year before & 0.059 & {$[0.002]^{* * *}$} \\
at least monthly volunteering 1 year before & 0.043 & {$[0.034]^{* *}$} \\
at least monthly at social gatherings 1 year before & 0.049 & {$[0.014]^{* *}$} \\
at least monthly helping out friends 1 year before & 0.013 & {$[0.419]$} \\
at least monthly local political participation 1 year before & -0.031 & {$[0.242]$} \\
unemployed & -0.603 & {$[0.000]^{* * *}$} \\
student & 0.088 & {$[0.139]$} \\
not working for other reasons & -0.0377 & {$[0.256]$} \\
retired & 0.061 & {$[0.199]$} \\
doing military or civil service & -0.183 & {$[0.138]$} \\
West & -0.392 & {$[0.111]$} \\
Year dummies & yes & \\
Lander dummies & yes &. \\
constant & 7.133 & {$[0.000]^{* * *}$} \\
\hline Number of observations & 53929 & \\
Overall R-square & 0.0215 & \\
F-stat & 26.88 & $\mathrm{p}>0.000$ \\
\hline \hline
\end{tabular}

Table 8: OLS regression with robust standard errors and individual fixed effects. The omitted categories are: employed, living in East Germany, without children, and single. Year and Lander dummies included. First column shows the coefficients from the regression $\left({ }^{*}\right.$ means significant at $10 \%,{ }^{* *}$ means significant at $5 \%,{ }^{* * *}$ means significant at $1 \%$.). The last column reports the p-value.

cant while volunteering becomes both positive and significant. It appears that volunteering is correlated with SWB more persistently than just helping out friends. 
Secondly, we further check the causal link between social capital and SWB by replacing in our baseline equation individual-level social capital indicators with Land-level indicators, namely the Land averages of social capital indicators. Land averages can be considered as rough proxies of social capital of individuals living in a given Land but, differently from individual measures, they can hardly be suspected to be endogenous. In this case we estimate the following equation:

$$
S W B_{i, t}=\alpha+\beta_{1} \cdot X_{i, t}^{d}+\gamma_{1} \cdot \ln \left(y_{i, t}\right)+\gamma_{2} \cdot \ln \left(\bar{y}_{i, t}\right)+\gamma_{3} \cdot \ln \left(y_{i, t-k}\right)+\delta \cdot \overline{S C}_{i, t}+e_{i, t}
$$

where $\overline{S C}_{i, t}$ stands for the Land averages of sociability proxies.

Detailed estimates are reported in table 9. As one can see, Land averages work almost as well as individual level indicators in terms of dimension and sgnificance of theur coefficients. The only exception is participating in sport activities, which seems to be irrelevant at the aggregate level. Finally, we stress that the estimates obtained with Land averages are also consistent with an interpretation emphasizing the role of local spillovers linked to the relational environment .

\section{Conclusions}

The trend of subjective well-being in Germany is slightly decreasing between 1996 and 2007, even considering West and East Germany separately. In this paper we quantified the extent to which the significant correlates of subjective well-being predict such a trend. In particular, we obtain a precise prediction of the overall subjective well-being variation as the result of contrasting tendencies on different life domains. The moderate increase in social capital especially in its relational component - has gone with a moderate increase in subjective wellbeing.

Substantial income growth has gone with a non-negligible but small increase in subjective well-being. This result appears to be based on the role of income comparisons and income adaptation which wiped out most of the benefits of income growth. The positive prediction associated with income growth might be slightly underestimated if one considers the shrinking of household size - which in our estimates predicts a moderate increase in SWB - as a proxy of increased personal access to economic resources. 
Average social capital indicators: East and West Germany in 1994-2007

\begin{tabular}{lcc}
\hline Dependent variable: Life satisfaction (1-10) & Coeff. & p-value \\
\hline \hline married & 0.074 & {$[0.078]^{*}$} \\
separated & -0.336 & {$[0.000]^{* * *}$} \\
divorced & -0.023 & {$[0.726]$} \\
widowed & -0.215 & {$[0.008]^{* * *}$} \\
age & -0.018 & {$[0.002]^{* * *}$} \\
age squared & 0.000 & {$[0.000]^{* * *}$} \\
household size & -0.136 & {$[0.000]^{* * *}$} \\
1 child & 0.122 & {$[0.004]^{* * *}$} \\
2 children & 0.160 & {$[0.002]^{* * *}$} \\
3 or more children & 0.393 & {$[0.000]^{* * *}$} \\
years of education & 0.009 & {$[0.264]$} \\
living with parents when 16 & -0.011 & {$[0.797]$} \\
log of monthly household income & 0.426 & {$[0.000]^{* * *}$} \\
log of reference income & -0.309 & {$[0.000]^{* * *}$} \\
log of monthly household income 3 years before & -0.073 & {$[0.000]^{* * *}$} \\
average at least monthly at church 1 & 0.058 & {$[0.024]^{* * *}$} \\
average at least monthly at cultural events & 0.101 & {$[0.000]^{* * *}$} \\
average at least monthly to cinema, pop concerts and similar & -0.021 & {$[0.466]$} \\
average at least monthly participating in sports 1 year before & 0.020 & {$[0.438]$} \\
average at least monthly volunteering & -0.043 & {$[0.119]$} \\
average at least monthly at social gatherings 1 year before & 0.197 & {$[0.000]^{* * *}$} \\
average at least monthly helping out friends & 0.076 & {$[0.001]^{* * *}$} \\
average at least monthly local political participation & -0.044 & {$[0.272]$} \\
unemployed & -0.549 & {$[0.000]^{* * *}$} \\
student & 0.034 & {$[0.509]$} \\
not working for other reasons & -0.035 & {$[0.250]$} \\
retired & 0.046 & {$[0.270]$} \\
doing military or civil service & -0.187 & {$[0.137]$} \\
West & -0.112 & {$[0.846]$} \\
Year dummies & $y e s$ & $\cdot$ \\
Lander dummies & yes & $\cdot$ \\
constant & 7.133 & {$[0.000]^{* * *}$} \\
\hline Number of observations & 60692 & \\
Overall R-square & 0.0218 & \\
F-stat & 33.89 & $\mathrm{p}>0.000$ \\
\hline \hline
\end{tabular}

Table 9: OLS regression with robust standard errors and individual fixed effects. The omitted categories are: employed, living in East Germany, without children, and single. Year and Lander dummies included. First column shows the coefficients from the regression $\left({ }^{*}\right.$ means significant at $10 \%,{ }^{* *}$ means significant at $5 \%,{ }^{* * *}$ means significant at $1 \%$.). The last column reports the p-value.

Among other socio-demographic controls, we found that ageing of the population predicts a large decrease in subjective well-being. This result appears to hinge crucially on the loss of 
satisfaction experienced in the old age. Moreover, an improvement of work status predicts a slight increase in subjective well-being that is just offset by the slight decrease predicted by the worsening of marital status. 


\section{A Definition of Variables}

satisfaction with life a scale of 11 degrees ranging from 10 , if respondent declares to be "completely satisfied", to 0 , if respondent declares to be "completely dissatisfied" (SOEP source variable: p1110107)

married 1 if respondent reports to be currently married, 0 otherwise (SOEP source variable: d1110407)

separated 1 if respondent reports to be currently separated, 0 otherwise (SOEP source variable: d1110407)

divorced 1 if respondent reports to be currently divorced, 0 otherwise (SOEP source variable: d1110407)

widowed 1 if respondent reports to be currently widowed, 0 otherwise (SOEP source variable: d1110407) female 1 if subject is female, 0 otherwise (SOEP source variable: d111021l) age number of years since born, 0 otherwise (SOEP source variable: d1110107) age squared age to the power of 2, 0 otherwise (SOEP source variable: $\mathrm{d} 1110107$ ) household size number of reported household members, 0 otherwise (SOEP source variable: d1110607)

1 child 1 if in the household there is one child, 0 otherwise (SOEP source variable: d1110707) 2 children 1 if in the household there is two children, 0 otherwise (SOEP source variable: d1110707)

3 or more children 1 if in the household there is three or more children, 0 otherwise (SOEP source variable: d1110707)

years of education number of years the respondent declared to have attended school, 0 otherwise (SOEP source variable: d1110907)

living with parents at 161 if respondent declares to be living with own parents at 16 years old, 0 otherwise (SOEP source vari-able: xh61)

Absolute income natural logarithm of Adjusted Monthly Household Net Income (Euro 2000) as provided in the SOEP, 0 otherwise (variable name: ahinc07)

Reference income natural logarithm of average Adjusted Monthly Household Net Income (Euro 2000) for a reference group as provided in the SOEP, 0 otherwise (variable name: ahinc07)

Past income Lag3 Three years temporal lag of the natural logarithm of Adjusted Monthly 
Household Net Income (Euro 2000) as provided in the SOEP, 0 otherwise (variable name: ahinc07)

monthly at church 1 if respondent reports to attend at least once a month church or religious institutions, 0 otherwise (SOEP source variable: xp0309)

monthly at culture events 1 if respondent reports to attend at least once a month cultural events, 0 otherwise (SOEP source vari-able: xp0301)

monthly at cinema 1 if respondent reports to go at least once a month to the cinema, 0 otherwise (SOEP source variable: xp0302)

monthly doing sport activities 1 if respondent reports to participate at least once a month to sport activities, 0 otherwise (SOEP sourcevariable: xp0303)

monthly at social gatherings 1 if respondent reports to visit at least once a month friends, relatives or neighbours, 0 otherwise (SOEP source variable: xp0305)

monthly helping friends 1 if respondent reports to help at least once a month friends, relatives or neighbours, 0 otherwise (SOEP source variable: $x p 0306$ )

monthly volunteering 1 if respondent perform volunteer work at least once a month in clubs, associations or social services, 0 otherwise (SOEP source variable: $x p 0307$ )

monthly local political participation 1 if respondent reports to participate at least once a month in citizens' action groups, politic-al parties, local government, 0 otherwise (SOEP source variable: $x p 0308$ )

unemployed 1 if respondent declares to be unemployed, 0 otherwise (SOEP source variable:lfs07)

student 1 if respondent declares to be student, 0 otherwise (SOEP source variable:lfs07)

non working 1 if respondent declares to be non-working, 0 otherwise (SOEP source variable:lfs07)

retired 1 if respondent declares to be retired, 0 otherwise (SOEP source variable:lfs07)

military/civil service 1 if respondent declares to be in military of civil service, 0 otherwise (SOEP source variable:lfs07)

west 1 if respondent declares to live in West Germany, 0 otherwise (SOEP source variable: 11110207) 


\section{B Descriptives}

\begin{tabular}{lccccc}
\hline \hline Variable & Obs & Mean & Std. Dev. & Min & Max \\
\hline life satisfaction & 338757 & 6.96 & 1.84 & 0 & 10 \\
married & 338757 & 0.62 & 0.49 & 0 & 1 \\
separated & 338757 & 0.02 & 0.13 & 0 & 1 \\
divorced & 338757 & 0.06 & 0.24 & 0 & 1 \\
widowed & 338757 & 0.06 & 0.24 & 0 & 1 \\
age & 338757 & 44.84 & 17.29 & 14 & 100 \\
household size & 338757 & 2.91 & 1.38 & 1 & 17 \\
1 child & 338757 & 0.19 & 0.39 & 0 & 1 \\
2 children & 338757 & 0.13 & 0.34 & 0 & 1 \\
3 or more children & 338757 & 0.05 & 0.22 & 0 & 1 \\
years of education & 327098 & 11.49 & 2.58 & 7 & 18 \\
living with parents at 16 & 338730 & 1.65 & 0.48 & 1 & 2 \\
monthly at church & 185066 & 0.39 & 0.49 & 0 & 1 \\
monthly at cultural events & 215958 & 0.48 & 0.5 & 0 & 1 \\
monthly at cinema & 215769 & 0.53 & 0.5 & 0 & 1 \\
monthly sport activities & 215148 & 0.47 & 0.5 & 0 & 1 \\
monthly at social gathering & 159673 & 0.78 & 0.41 & 0 & 1 \\
monthly help from friends & 159378 & 0.4 & 0.49 & 0 & 1 \\
monthly volunteering & 215353 & 0.23 & 0.42 & 0 & 1 \\
monthly local political participation & 215135 & 0.07 & 0.26 & 0 & 1 \\
unemployed & 338757 & 0.05 & 0.23 & 0 & 1 \\
student & 338757 & 0.04 & 0.2 & 0 & 1 \\
non working & 338757 & 0.13 & 0.34 & 0 & 1 \\
retired & 338757 & 0.14 & 0.34 & 0 & 1 \\
military/civil service & 338757 & 0 & 0.05 & 0 & 1 \\
west & 338757 & 0.78 & 0.41 & 0 & 1 \\
\hline \hline
\end{tabular}

Table 10: Descriptive statistics over all SOEP samples and available years up to 2007. 


\section{Construction of Reference Groups}

We defined reference group of individual $i$ in year $t$ as the sub-sample of individuals in Germany living in $i$ 's region (west or east) in year $t$ same year with education and age similar to $i$ 's. More precisely, reference groups are defined using the following four different variables:

- Year

a scalar containing all years between 1984 and 2007;

- West

a dummy variable indicating living in West Germany;

- Age_cls

a scalar indicating whether individuals are younger than 30, between 31 and 60 and 61 or older;

- Yreduc_cls

a three-value variable indicating whether individuals went through less than 11 years of education, between 11 and 12 years, or 13 or more years of education.

We used the following Stata 9.0 syntax to construct groups:

egen Ref.Group = group (year west age_cls2 yreduc_cls2)

\section{if !missing (year,west, age_cls2,yreduc_cls2)}

In this way, we generated a new variable assuming a different value for each possible group. This procedure generated 378 reference groups. Subsequently, we computed the income of the reference group as the mean value of the incomes of all the individuals in each reference group:

bys Ref.Group: egen ref.income = mean(income) if !missing(income)

Finally, we took the log of reference income:

gen lnref.income $=\ln ($ ref.income) 


\section{Analysis of Sociability Indicators}

\begin{tabular}{l|cccccccc}
\hline \hline & $(1)$ & $(2)$ & $(3)$ & $(4)$ & $(5)$ & $(6)$ & $(7)$ & $(8)$ \\
\hline (1) monthly at religious events & 1 & & & & & & & \\
(2) monthly at cultural events & 0.15 & 1 & & & & & & \\
(3) monthly at cinema & 0 & 0.42 & 1 & & & & & \\
(4) monthly playing sport & 0.07 & 0.34 & 0.44 & 1 & & & & \\
(5) monthly at social gathering & 0.09 & 0.18 & 0.22 & 0.2 & 1 & & & \\
(6) monthly helping friends & 0.05 & 0.1 & 0.12 & 0.12 & 0.3 & 1 & & \\
(7) monthly volunteering & 0.22 & 0.24 & 0.18 & 0.25 & 0.1 & 0.15 & 1 & \\
(8) monthly political active & 0.13 & 0.16 & 0.1 & 0.13 & 0.03 & 0.08 & 0.39 & 1 \\
\hline \hline
\end{tabular}

Table 11: Correlation matrix of sociability indicators 


\begin{tabular}{|c|c|c|c|c|c|c|c|c|}
\hline \multicolumn{3}{|c|}{ Principal components/correlation } & \multicolumn{4}{|c|}{ Observations: 115581} & \multirow{2}{*}{\multicolumn{2}{|c|}{ Cumulative }} \\
\hline Component & \multicolumn{2}{|c|}{ Eigenvalue } & \multicolumn{2}{|c|}{ Difference } & \multicolumn{2}{|c|}{ Proportion } & & \\
\hline Comp1 & \multicolumn{2}{|c|}{2.32} & \multicolumn{2}{|c|}{1.07} & \multicolumn{2}{|c|}{0.29} & \\
\hline Comp2 & \multicolumn{2}{|c|}{1.25} & \multicolumn{2}{|c|}{0.14} & \multicolumn{2}{|c|}{0.16} & \multicolumn{2}{|c|}{$\begin{array}{l}0.29 \\
045\end{array}$} \\
\hline Comp3 & \multicolumn{2}{|c|}{1.11} & \multicolumn{2}{|c|}{0.2} & \multicolumn{2}{|c|}{0.14} & \multicolumn{2}{|c|}{0.58} \\
\hline Comp4 & \multicolumn{2}{|c|}{0.91} & \multicolumn{2}{|c|}{0.24} & \multicolumn{2}{|c|}{0.11} & \multicolumn{2}{|c|}{0.7} \\
\hline Comp5 & \multicolumn{2}{|c|}{0.67} & \multicolumn{2}{|c|}{0.01} & \multicolumn{2}{|c|}{0.08} & \multicolumn{2}{|c|}{0.78} \\
\hline Comp6 & \multicolumn{2}{|c|}{0.66} & \multicolumn{2}{|c|}{0.08} & \multicolumn{2}{|c|}{0.08} & \multicolumn{2}{|c|}{0.86} \\
\hline Comp7 & \multicolumn{2}{|c|}{0.58} & \multicolumn{2}{|c|}{0.06} & \multicolumn{2}{|c|}{0.07} & \multicolumn{2}{|c|}{0.94} \\
\hline Comp8 & & & & & & & & \\
\hline Principal components ( & igenvecto & & & & & & & \\
\hline Variable & Comp1 & Comp2 & Comp3 & Comp4 & Comp5 & Comp6 & Comp7 & Comp8 \\
\hline (1) monthly at religious events & 0.2 & 0.43 & 0.24 & 0.79 & -0.12 & -0.08 & 0.25 & 0.14 \\
\hline (2) monthly at cultural events & 0.44 & -0.09 & -0.27 & 0.22 & -0.08 & 0.68 & -0.2 & -0.41 \\
\hline (3) monthly at cinema & 0.44 & -0.32 & -0.33 & -0.02 & -0.03 & 0.05 & 0.17 & 0.75 \\
\hline (4) monthly playing sport & 0.44 & -0.2 & -0.27 & 0 & -0.11 & -0.64 & 0.23 & -0.46 \\
\hline (5) monthly at social gathering & 0.3 & -0.34 & 0.5 & 0.12 & 0.7 & -0.06 & -0.16 & -0.03 \\
\hline (6) monthly helping friends & 0.25 & -0.19 & 0.66 & -0.28 & -0.58 & 0.14 & 0.17 & -0.02 \\
\hline (7) monthly volunteering & 0.39 & 0.46 & 0.04 & -0.2 & -0.11 & -0.24 & -0.71 & 0.15 \\
\hline (8) monthly political active & 0.29 & 0.55 & 0 & -0.44 & 0.35 & 0.18 & 0.51 & -0.05 \\
\hline
\end{tabular}

Table 12: Principal component analysis of sociability indicators 


\section{References}

Antoci, A., F. Sabatini, and M. Sodini (2011). The solaria syndrome: Social capital in a growing hyper-technological economy. Journal of Economic Behavior \& Organization.

Bartolini, S., E. Bilancini, and M. Pugno (2011). Did the decline in social connections depress Americans' happiness? forthcoming Social Indicators Research.

Bartolini, S. and L. Bonatti (2008). "Endogenous growth, decline in social capital and expansion of market activities”. Journal of Economic Behavior \& Organization 67, 917-926.

Becchetti, L., A. Pelloni, and F. Rossetti (2008). "Relational goods, sociability and happiness". Kyklos 61(3)(343 - 363).

Becchetti, L., E. G. Ricca, and A. Pelloni (2011). "The 60es turnaround as a test on the causal relationship between sociability and happiness". forthcoming Journal of Economic Behavior \& Organization.

Bilancini, E. and S. D'Alessandro (2011). Long run welfare under externalities in consumption, leisure, and production: A case for happy de-growth vs. unhappy growth. forthcoming Ecological Economics.

Blanchflower, D. (2008, February). International evidence on well-being. IZA Discussion Papers 3354.

Blanchflower, D. and A. Oswald (2004a). “Is well-being U-shaped over the life cycle?”. Social Science \& Medicine (66), 1733-1749.

Blanchflower, D. and A. Oswald (2004b). "Well-Being Over Time in Britain and the USA". Journal of Public Economics (88), 1359-1386.

Bruni, L. and L. Stanca (2008). "Watching alone: Relational goods, television and happiness". Journal of Economic Behavior \& Organization 65, 506-528.

Caporale, G., Y. Georgellis, N. Tsitsianis, and Y. Yin (2009). Income and happiness across europe: Do reference values matter? Journal of Economic Psychology 30(1), 42-51. 
Charles, S., C. Reynolds, and M. Gatz (2001). Age-related differences and change in positive and negative affect over 23 years. Journal of Personality and Social Psychology 80, 136151.

Clark, A., P. Frijters, and M. Shields (2008). "Relative Income, Happiness, and Utility: An Explanation for the Easterlin Paradox and Other Puzzles”. Journal of Economic Literature (46), 99-144.

Clark, A. and A. Oswald (2006). "The curved relationship between subjective well-being and age". PSE working paper n.29.

Corazzini, L., L. Esposito, and F. Majorano (2011). Exploring the absolutist vs relativist perception of poverty using a cross-country questionnaire survey. Journal of Economic Psychology 32(2), 273-283.

Costa, D. and M. Kahn (2003). "Understanding the american decline in social capital”. 56, $17-46$.

D’Ambrosio, C. and J. Frick (2008). "Individual well-being in a dynamic perspective". Working papers 64, ECINEQ, Society for the Study of Economic Inequality.

Deaton, A. (2008). Income, health and well-being around the World: evidence from the Gallup World Poll. Journal of Economic Perspectives, 53 - 72.

Di Tella, R., J. Haisken-De New, and R. MacCulloch (2007). "Happiness adaptation to income and to status in an individual panel". NBER working papers (13159).

Di Tella, R. and R. MacCulloch (2008a). "Gross national happiness as an answer to the Easterlin paradox?". Journal of Development Economics 86, 22-42.

Di Tella, R. and R. MacCulloch (2008b). "Happiness adaptation to income 'basic needs' ". NBER working papers (14539).

Diener, E., E. Sandvik, L. Seidlitz, and M. Diener (1993). "The relationship between income and subjective well-being: relative or absolute?”. Social Indicators Research 28, 195-223.

Dolan, P., T. Peasgood, and M. White (2008). Do we really know what makes us happy? A review of the economic literature on the factors associated with subjective well-being. Journal of Economic Psychology 29(1), 94-122. 
Duesenberry, J. S. (1949). Income, Savings and the Theory of Consumer Behaviour. Cambridge, MA: Harvard University Press.

Durlauf, S. N. (2001). “A Framework for the Study of Individual Behaviour and Social Interactions". Social Methodology (31), 47-87.

Durlauf, S. N. (2002). “On the empirics of social capital”. Economic Journal (112).

Easterlin, E. A. (1974). "Does Economic Growth Improve the Human Lot? Some Empirical Evidence". Nations and Households in Economic Growth (eds. P.A. David), 89-125.

Easterlin, E. A. (1995). "Will Rising the Incomes of All Increase the Happiness of All?". Journal of Economic Behaviour \& Organization (27), 35-47.

Easterlin, R. (2006). Life cycle happiness and its sources: Intersections of psychology, economics, and demography. Journal of Economic Psychology 27(4), 463-482.

Easterlin, R. and L. Angelescu (2009). "happiness and growth the world over: Time series evidence on the happiness-income paradox". IZA Discussion Paper (4060).

Falk, A. and M. Knell (2004, October). "choosing the joneses: endogenous goals and reference standards". Scandinavian Journal of Economics 106(3), pp. 417 - 435.

Ferrer-i-Carbonell, A. (2005). "Income and Well-Being: An Empirical Analysis of the Comparison Income Effect”. Journal of Public Economics (89), 997-1019.

Ferrer-i-Carbonell, A. and P. Frijters (2004a). "How Important is Methodology for the Estimates of the Determinant of Happiness?". The Economic Journal (114), 641-659.

Ferrer-i-Carbonell, A. and P. Frijters (2004b). "How Important is Methodology for the Estimates of the Determinant of Happiness?". The Economic Journal (114), 641-659.

Frederick, S. and G. Loewenstein (1999). "hedonic adaptation". In D. Kanheman and E. Diener (Eds.), The foundations of hedonic psychology. Russel Sage.

Frey, B. and A. Stutzer (2000). "Happiness, Economy and Institutions". Economic Journal (110), 918-938. 
Frey, B. and A. Stutzer (2002). Happiness and Economics. New Jersey: Princeton University Press.

Frick, J., S. Jenkins, D. Lillard, O. Lipps, and M. Wooden (2007). The cross-national equivalent file (cnef) and its member country household panel studies. Schmollers Jahrbuch 127(4), 627-654.

Gerstorf, D., N. Ram, J. Goebel, J. Schupp, U. Lindenberger, and G. Wagner (2010). Where people live and die makes a difference: individual and geographic disparities in well-being progression at the end of life. DIW Berlin SOEP papers 287.

Gerstorf, D., N. Ram, G. Mayraz, M. Hidajat, U. Lindenberger, G. Wagner, and J. Schupp (2010). Late-life decline in well-being across adulthood in germany, the uk and the us: something is seriously wrong at the end of life. DIW Berlin SOEP papers 286.

Gui, M. and R. Sugden (2005). Economics and social interaction. Cambridge: Cambridge University Press.

Haisken-DeNew, J. and M. Hahn (2010). Panelwhiz: Efficient data extraction of complex panel data sets-an example using the german soep. Schmollers Jahrbuch 130(4), 643-654.

Helliwell, J. (2001). Social capital, the economy and well-being. In E. D. Andrew Sharpe, R. France St-Hilaire, Vice-President, and D. Keith Banting (Eds.), The Review of Economic Performance and Social Progress 2001: The Longest Decade: Canada in the 1990s, Volume 1 of The Review of Economic Performance and Social Progress. Centre for the Study of Living Standards \& The Institutute for Research on Public Policy.

Helliwell, J. (2006). “Well-being, social capital and public policy: What's new?”. Economic Journal 116, C34-45.

Helliwell, J. and R. Putnam (2004). "The social context of well-being”. Philosophical Transactions 359(1449), pp. 1435 - 1446.

Hirschman, A. (1973). "The changing tolerance for income inequality in the course of economic development". Quarterly Journal of Economics (87), 544-566.

Kapteyn, A. and T. Wansbeek (1985). "The individual welfare function: A review”. Journal of Economic Psychology 6, pp. 333-363. 
Ladd, E. (1996). The data just don't show erosion of America's social capital. Public Perspective $7,1-30$.

Layard, R. (2005). Happiness: Lessons From a New Science. The Penguin Press.

Layard, R. and S. Nickell (2009). "Does relative income matter? Are the critics right?". In D. Kahneman, E. Diener, and J. Helliwell (Eds.), International differences in well-being. Oxford University Press.

Lim, C. and R. Putnam (2008). "Praying alone is no fun: Religion, social networks, and subjective well-being”. Harvard University - mimeo.

Luttmer, E. F. (2005). “Neighbors as Negatives: Relative Earnings and Well-Being”. Quarterly Journal of Economics (120), 936-1002.

McBride, M. (2001). "Relaitve-Income Effects on Subjective Well-Being in the CrossSection”. Journal of Economic Behavior \& Organization (45), 251-278.

Mroczek, D. and A. Spiro (2005). "Change in life satisfaction during adulthood: Findings from the veterans affairs normative aging study". Journal of Personality and Social Psychology 88, 189-202.

OECD (2001). The evidence on social capital. In The well-being of nations: the role of human and social capital, pp. $39-63$. OECD, Paris.

Paxton, P. (1999). Is social capital declining in the United States? A multiple indicator assessment. American Journal of Sociology 105, 88 - 127.

Putnam, R. D. (2000). Bowling alone: The collapse and revival of american community. New York: Simon \& Schuster.

Robinson, R. and E. Jackson (2001). Is trust in others declining in America? An age period cohort analysis. Social Science Research 30, 117 - 145.

Sabatini, F. (2009). Social capital as social networks: a new framework for measurement and an empirical analysis of its determinants and consequences. Journal of Socioeconomics 38(3), 429-442. 
Senik, C. (2004). "When information dominates comparison: Learning from russian subjective panel data". Journal of Public Economics (88), 2099-2133.

Stutzer, A. (2004). "The Role of Income Aspirations in Individual Happiness". Journal of Economic Behaviour \& Organization (54), 89-109.

Uhlaner, C. (1989). âĂIJrelational goodsâĂİ and participation: incorporating sociability into a theory of rational action. Public Choice 62(3), 253-285.

Van Landeghem, B. G. (2008). "Human well-being over the life cycle: Longitudinal evidence from a 20-year panel". LICOS Discussion Paper Series 213.

Van Praag, B., B. M. Frijters, and A. Ferrer-I-Carbonell (2003). "Appraisal of Life: "area” versus "Dimension" Conceptualizations". Journal Economic Behavior and Organization (51), $29-49$.

Van Praag, B., P. Frijters, and A. Ferrer-i Carbonell (2003). The anatomy of subjective wellbeing. Journal of Economic Behavior \& Organization 51(1), 29-49.

Veblen, T. (1899). The Theory of the Leisure Class. New York: Macmillan.

Vendrik, M. and J. Hirata (2007). "experienced versus decision utility of income: relative or absolute happiness". In L. Bruni and P. Porta (Eds.), Handbook on the Economics of Happiness. Cheltenham: Edward Elgar, S. 185 - 208.

Vendrik, M. and G. B. Woltjer (2007). "Happiness and loss aversion: Is utility concave or convex in relative income?". The Journal of Public Economics 91, 1423-1448.

Wagner, G., J. Frick, and J. Schupp (2007). The german socio-economic panel study (soep)evolution, scope and enhancements. Schmollers Jahrbuch 127(1), 139-169. 